\title{
Reversible and irreversible processing of biogenic olefins on acidic aerosols
}

\author{
J. Liggio and S.-M. Li
}

Air Quality Research Division, Atmospheric Science and Technology Directorate, Science and Technology Branch, Environment Canada 4905 Dufferin Street, Toronto, Ontario, Canada, M3H 5T4, Canada

Received: 25 July 2007 - Published in Atmos. Chem. Phys. Discuss.: 14 August 2007

Revised: 12 October 2007 - Accepted: 6 March 2008 - Published: 9 April 2008

\begin{abstract}
Recent evidence has suggested that heterogeneous chemistry of oxygenated hydrocarbons, primarily carbonyls, plays a role in the formation of secondary organic aerosol (SOA); however, evidence is emerging that direct uptake of alkenes on acidic aerosols does occur and can contribute to SOA formation. In the present study, significant uptake of monoterpenes, oxygenated monoterpenes and sesquiterpenes to acidic sulfate aerosols is found under various conditions in a reaction chamber. Proton transfer mass spectrometry is used to quantify the organic gases, while an aerosol mass spectrometer is used to quantify the organic mass uptake and obtain structural information for heterogeneous products. Aerosol mass spectra are consistent with several mechanisms including acid catalyzed olefin hydration, cationic polymerization and organic ether formation, while measurable decreases in the sulfate mass on a per particle basis suggest that the formation of organosulfate compounds is also likely. A portion of the heterogeneous reactions appears to be reversible, consistent with reversible olefin hydration reactions. A slow increase in the organic mass after a fast initial uptake is attributed to irreversible reactions, consistent with polymerization and organosulfate formation. Uptake coefficients $(\gamma)$ were estimated for a fast initial uptake governed by the mass accommodation coefficient $(\alpha)$ and ranged from $1 \times 10^{-6}-2.5 \times 10^{-2}$. Uptake coefficients for a subsequent slower reactive uptake ranged from $1 \times 10^{-7}-1 \times 10^{-4}$. These processes may potentially lead to a considerable amount of SOA from the various biogenic hydrocarbons under acidic conditions, which can be highly significant for freshly nucleated aerosols, particularly given the large array of atmospheric olefins.
\end{abstract}

Correspondence to: J. Liggio

(john.liggio@ec.gc.ca)

\section{Introduction}

Gas-phase oxidation of hydrocarbons has been considered a key step in the formation of secondary organic aerosols (SOA) in the atmosphere. This process is an area of significant interest due to its climatic relevance (Pilinis, et al., 1995), its effect on regional visibility (Eldering and Cass, 1996), and its potential for negative health effects (Goldberg, et al., 2003; Hannigan, et al., 1998). Comprehension of these effects is complicated by the fact that the composition of SOA greatly determines the extent of these effects. Consequently, there is a need to determine the mechanisms of formation and the nature of SOA composition, particularly from biogenic sources.

Emissions from terrestrial vegetation are a significant source of non methane hydrocarbons (NMHCs) globally, contributing upwards of $850 \mathrm{Tg}$ of organic carbon per year, considerably surpassing annual anthropogenic emissions (125 Tg/year) (Hoffmann, et al., 1997). Emissions of these biogenic volatile organic compounds (BVOCs), including isoprene, monoterpenes, oxygenated terpenes and sesquiterpenes, are an important source of secondary organic aerosol (SOA), particularly due to their high atmospheric concentrations and their intense reactivities with atmospheric oxidants. Although many products from the oxidation of biogenic NMHCs are volatile and remain in the gas-phase, a significant number possess vapor pressures sufficiently low such that their partitioning to aerosols occurs. Many of these low volatility products have been observed in both laboratory generated biogenic SOA (Boge, et al., 2006; Kroll, et al., 2006) and ambient aerosols over forested regions (Kavouras, et al., 1999).

Recent work has shown heterogeneous and liquid phase reactions, often leading to polymeric material, as a potential route for SOA formation from volatile and semi-volatile oxidation products of biogenic and anthropogenic origin (Jang, et al., 2003; Kroll, et al., 2005; Liggio and Li, 2006b;

Published by Copernicus Publications on behalf of the European Geosciences Union. 


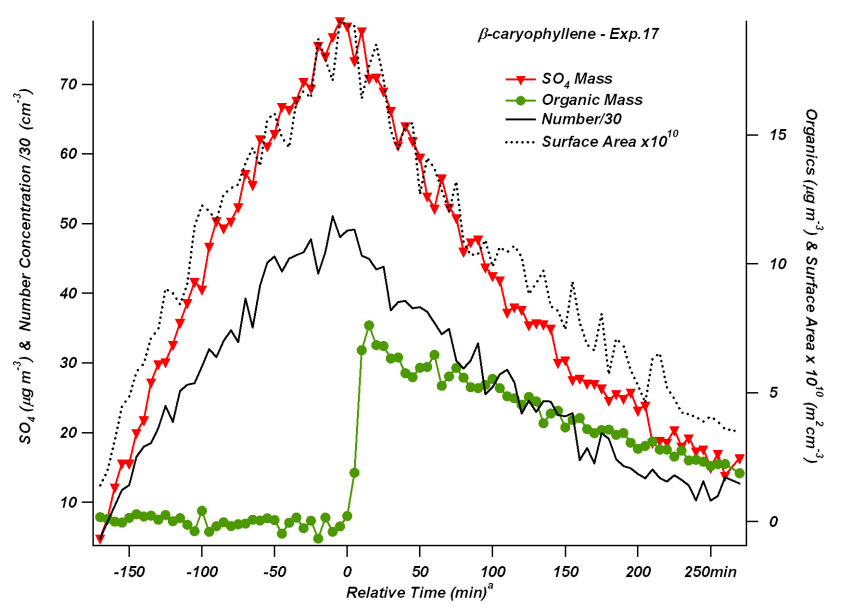

Fig. 1. Example of the time dependent mass loading curves $\left(\mathrm{SO}_{4}\right.$ and Organics), particle number concentration and total surface area for the uptake of biogenic species. (a) Time $=0$ indicates the injection of the olefin into the chamber.

Noziere and Riemer, 2003; Gao et al., 2004; Hastings et al., 2005; Kalberer et al., 2004; Tolocka et al., 2004). This pathway may aid in explaining the current underestimation of SOA mass by global models (Heald, et al., 2005), and could prove important with respect to $\mathrm{CCN}$ activity. Heterogeneous reactions have been proposed to lead to the transformation of VOCs and SVOCs to various high molecular weight compounds, oligomers or organosulfate species, specifically via compounds containing oxygenated functional groups (carbonyls and alcohols). Several mechanisms, including oligomer formation, hydration, hemi-acetal and acetal formation, polymerization (Jang and Kamens, 2001), aldol condensation (Noziere and Riemer, 2003) and organosulfate formation (Iinuma, et al., 2007a; Iinuma, et al., 2007b; Liggio and Li, 2006a; Surratt, et al., 2007), have been proposed to explain observed heterogeneous products and possible acid catalysis in laboratory studies.

Although oligomer formation from oxidized products of primary hydrocarbons is now well known, comparatively little is known regarding the SOA forming potential of primary unsaturated biogenic hydrocarbons (e.g., alkenes). Bulk liquid studies suggested that acid catalyzed polymerization of isoprene may be feasible (Limbeck, et al., 2003), and more elaborate chamber studies have demonstrated that indeed isoprene and $\alpha$-pinene can be taken up significantly by acidic aerosols via polymerization of these olefins and subsequent polymer hydration (Liggio, et al., 2007). However, it has been unclear whether reactions leading to polymers and oligomers are reversible, which in turn determines their importance to SOA formation in the atmosphere. Evidence for both scenarios has been observed with respect to the heterogeneous uptake of glyoxal (Hastings, et al., 2005; Kroll, et al., 2005; Liggio, et al., 2005).

Extending the previous work on isoprene and $\alpha$-pinene
(Liggio, et al., 2007), the present paper reports on the results of a series of lab studies on the direct uptake of biogenic olefin species, including various monoterpenes, oxygenated monoterpenes, and sesquiterpenes, to acidic sulfate aerosols. The organic mass uptake, reaction mechanisms for the heterogeneous reactions of several of these compounds, the reversibility of such reactions, and the importance of this process in the ambient atmosphere are discussed.

\section{Methodology}

Eight terpenoid species were exposed to acidic sulfate seed aerosols in a $2 \mathrm{~m}^{3}$ Teflon reaction chamber, enclosed in a framed aluminium container to prevent potential photochemistry. The details of the chamber design and configuration have been given previously (Liggio and $\mathrm{Li}, 2006 \mathrm{~b}$ ), with slight modifications described herein. A summary of the initial aerosol composition, the hydrocarbon gases and other initial conditions is given in Table 1 . In a typical experiment, the chamber was filled first with aerosols of known $\mathrm{H}_{2} \mathrm{SO}_{4} /\left(\mathrm{NH}_{4}\right)_{2} \mathrm{SO}_{4}$ composition and size, to a concentration of approximately $1000-3000 \mathrm{~cm}^{-3}$, followed by the addition of a gaseous monoterpene or sesquiterpene (Sigma-Aldrich, $>98 \%$ ) at a given relative humidity (RH, 1.4-73\%). The relative humidity was controlled by injecting de-ionized and organic free water onto the surface of a resistively heated element within the chamber, prior to and during the addition of aerosols.

\subsection{Aerosol generation}

Aerosols were generated by atomizing a solution consisting of approximately $0.011 \mathrm{M}\left(\mathrm{NH}_{4}\right)_{2} \mathrm{SO}_{4}$ and $0.3 \mathrm{M} \mathrm{H}_{2} \mathrm{SO}_{4}$ with a constant volume atomizer (TSI Inc.) at different RH (and slight differences in temperature) to give the different acidities in the aerosols of Table 1. Approximately mono-dispersed aerosols, of 300-400 nm in diameter (463527 Vacuum aerodynamic diameter), were selected with a scanning differential mobility analyzer (DMA, TSI Inc.) and introduced into the chamber over a period of several hours or until a sufficient particle concentration was obtained. Drifting of the DMA sheath and aerosol flows over this time, and differences in water uptake from one experiment to the next, account for the stated size range.

\subsection{Gas delivery and measurement}

The terpenoid gases were introduced to the chamber, one for each experiment, by injecting their pure liquids into a stream of zero air (Aadco Inc.) which contains no measurable levels of oxidant or other contaminants. The terpenoid compounds were chosen to span the range of compound classes that are commonly observed in the ambient atmosphere. These include non-oxygenated and oxygenated monoterpenes and sesquiterpenes (Table 1). Structures associated 
Table 1. Initial gas and aerosol parameters associated with each experiment

\begin{tabular}{|c|c|c|c|c|c|c|}
\hline Exp.\# & Species & {$[\mathrm{Gas}]^{\mathrm{a}}(\mathrm{ppm})$} & RH (\%) & Initial Seed Aerosol Composition $\left(\text { moles } \mathrm{kg}^{-1}\right)^{\mathrm{b}}$ & Initial Aerosol pH & Initial Diam. $(\mathrm{nm})( \pm \sigma)^{\mathrm{c}}$ \\
\hline \multicolumn{7}{|c|}{ Monoterpenes } \\
\hline 1 & Limonene & 2.3 & 1.6 & $\mathrm{H}^{+}=33.2 \mathrm{HSO}_{4}^{-}=34.1 \mathrm{SO}_{4}^{2-}=0.82 \mathrm{NH}_{4}^{+}=2.5$ & -4.74 & $463(4.6)$ \\
\hline 2 & Limonene & 0.40 & 3.1 & $\mathrm{H}^{+}=28.0 \mathrm{HSO}_{4}^{-}=28.1 \mathrm{SO}_{4}^{2-}=1.0 \mathrm{NH}_{4}^{+}=2.1$ & -4.40 & $482(2.0)$ \\
\hline 3 & Limonene & 1.1 & 18.8 & $\mathrm{H}^{+}=15.8 \mathrm{HSO}_{4}^{-}=13.6 \mathrm{SO}_{4}^{\frac{4}{2}-}=1.7 \mathrm{NH}_{4}^{+}=1.1$ & -3.10 & $517(3.4)$ \\
\hline 4 & Limonene & 1.4 & 45.8 & $\mathrm{H}^{+}=10.0 \mathrm{HSO}_{4}^{-}=6.8 \mathrm{SO}_{4}^{2-}=1.9 \mathrm{NH}_{4}^{+}=0.63$ & -2.05 & $527(4.2)$ \\
\hline 5 & $\beta$-pinene & 1.8 & 3.3 & $\mathrm{H}^{+}=27.5 \mathrm{HSO}_{4}^{-}=27.5 \mathrm{SO}_{4}^{2-}=1.0 \mathrm{NH}_{4}^{+}=2.1$ & -4.37 & $468(2.5)$ \\
\hline 6 & $\beta$-pinene & 1.8 & 17.1 & $\mathrm{H}^{+}=16.4 \mathrm{HSO}_{4}^{-}=14.3 \mathrm{SO}_{4}^{2^{-}-}=1.6 \mathrm{NH}_{4}^{+}=1.15$ & -3.20 & $515(3.9)$ \\
\hline 7 & $\beta$-pinene & 1.8 & 24.2 & $\mathrm{H}^{+}=14.3 \mathrm{HSO}_{4}^{-}=11.7 \mathrm{SO}_{4}^{2-}=1.8 \mathrm{NH}_{4}^{+}=1.0$ & -2.85 & $476(2.9)$ \\
\hline 8 & $\beta$-pinene & 1.8 & 54.2 & $\mathrm{H}^{+}=8.7 \mathrm{HSO}_{4}^{-}=5.5 \mathrm{SO}_{4}^{2-}=1.9 \mathrm{NH}_{4}^{+}=0.53$ & -1.78 & $503(3.6)$ \\
\hline 9 & 3-Carene & 1.0 & 2.4 & $\mathrm{H}^{+}=29.7 \mathrm{HSO}_{4}^{-}=30.1 \mathrm{SO}_{4}^{2-}=0.93 \mathrm{NH}_{4}^{+}=2.2$ & -4.54 & $498(3.5)$ \\
\hline 10 & 3-Carene & 1.1 & 40.0 & $\mathrm{H}^{+}=11.0 \mathrm{HSO}_{4}^{-}=7.9 \mathrm{SO}_{4}^{2-}=1.9 \mathrm{NH}_{4}^{+}=0.71$ & -2.25 & $491(4.4)$ \\
\hline 11 & 3-Carene & 1.0 & 73.0 & $\mathrm{H}^{+}=5.9 \mathrm{HSO}_{4}^{-}=3.3 \mathrm{SO}_{4}^{2^{-}-}=1.5 \mathrm{NH}_{4}^{+}=0.35$ & -1.17 & $491(2.7)$ \\
\hline 12 & Linalool & 0.08 & 1.4 & $\mathrm{H}^{+}=34.3 \mathrm{HSO}_{4}^{-}=35.4 \mathrm{SO}_{4}^{2-}=0.79 \mathrm{NH}_{4}^{+}=2.6$ & -4.80 & $464(4.8)$ \\
\hline 13 & Linalool & 0.42 & 47.5 & $\mathrm{H}^{+}=9.7 \mathrm{HSO}_{4}^{-}=6.5 \mathrm{SO}_{4}^{2-}=1.9 \mathrm{NH}_{4}^{+}=0.61$ & -2.00 & $517(5.0)$ \\
\hline 14 & Geraniol & 0.03 & 2.1 & $\mathrm{H}^{+}=30.8 \mathrm{HSO}_{4}^{-}=31.4 \mathrm{SO}_{4}^{2-}=0.88 \mathrm{NH}_{4}^{+}=2.3$ & -4.62 & $506(5.4)$ \\
\hline \multicolumn{7}{|c|}{ Sesquiterpenes } \\
\hline 15 & $\beta$-Caryophyllene & 0.15 & 1.4 & $\mathrm{H}^{+}=34.2 \mathrm{HSO}_{4}^{-}=35.2 \mathrm{SO}_{4}^{2-}=0.78 \mathrm{NH}_{4}^{+}=2.6$ & -4.81 & $473(6.8)$ \\
\hline 16 & $\beta$-Caryophyllene & 0.10 & 1.8 & $\mathrm{H}^{+}=32.3 \mathrm{HSO}_{4}^{-}=33.1 \mathrm{SO}_{4}^{2-}=0.84 \mathrm{NH}_{4}^{+}=2.5$ & -4.70 & $486(4.4)$ \\
\hline 17 & $\beta$-Caryophyllene & 0.19 & 18.8 & $\mathrm{H}^{+}=15.8 \mathrm{HSO}_{4}^{-}=13.5 \mathrm{SO}_{4}^{2-}=1.7 \mathrm{NH}_{4}^{+}=1.1$ & -3.11 & $517(3.1)$ \\
\hline 18 & $\beta$-Caryophyllene & 0.20 & 55.5 & $\mathrm{H}^{+}=8.5 \mathrm{HSO}_{4}^{-}=5.4 \mathrm{SO}_{4}^{2-}=1.8 \mathrm{NH}_{4}^{+}=0.52$ & -1.74 & $523(4.3)$ \\
\hline 19 & $\alpha$-Humullene & 0.12 & 1.4 & $\mathrm{H}^{+}=34.3 \mathrm{HSO}_{4}^{-}=35.4 \mathrm{SO}_{4}^{2-}=0.79 \mathrm{NH}_{4}^{+}=2.6$ & -4.80 & $488(6.3)$ \\
\hline 20 & $\alpha$-Humullene & 0.30 & 66.5 & $\mathrm{H}^{+}=6.9 \mathrm{HSO}_{4}^{-}=4.0 \mathrm{SO}_{4}^{2-}=1.7 \mathrm{NH}_{4}^{+}=0.41$ & -1.39 & $498(3.0)$ \\
\hline 21 & Nerolidol & 0.64 & 2.5 & $\mathrm{H}^{+}=29.5 \mathrm{HSO}_{4}^{-}=29.9 \mathrm{SO}_{4}^{2-}=0.93 \mathrm{NH}_{4}^{+}=2.2$ & -4.52 & $511(7.0)$ \\
\hline
\end{tabular}

${ }^{a}$ Mean of the measurements during the experiment.

$\mathrm{b}$ Based on equilibrium thermodynamic calculation (Clegg et al., 1998).

c Initial mean vacuum aerodynamic diameter as measured by the Q-AMS.

with the studied compounds are given in Fig. 1 - Supporting Information http://www.atmos-chem-phys.net/8/2039/2008/ acp-8-2039-2008-supplement.pdf. The gas phase concentration in the chamber during a given experiment was monitored on a $1 \mathrm{~s} \mathrm{time} \mathrm{resolution} \mathrm{with} \mathrm{a} \mathrm{Proton} \mathrm{Transfer} \mathrm{Reaction} \mathrm{Mass}$ Spectrometer (PTR-MS, Ionicon Analytik Inc.), the operation principles and application of which have been described previously (Steinbacher, et al., 2004). Briefly, $\mathrm{H}_{3} \mathrm{O}^{+}$ions are used to ionize gases via the transfer of a proton, yielding primarily $\mathrm{M}+1$ ions with little or no fragmentation. The ionization efficiency is based upon the proton affinity, which is significant for most unsaturated compounds. Ions are then accelerated into a quadrupole mass spectrometer for detection which was operated in the single ion mode. The response of the PTR-MS for a species was calibrated with a known gas phase concentration, produced by injection of a given mass of the species into a known flow of zero air. The PTR-MS was directly connected to the chamber via a $10 \mathrm{~cm}$ length of $1 / 8$ Teflon tubing which was continuously heated to approximately $60 \mathrm{C}$, to minimize adsorption of gases and subsequent sample contamination. The sampling line was automatically purged with zero air every $5 \mathrm{~min}$ to reduce sample carry-over. The gas phase concentration of most species in the chamber was constant to within $<5-\sim 20 \%$ over the time scales of each experiment. It is estimated that the uncertainty in the gas phase measurement is $20 \%$. Examples of the PTR-MS results are given in Fig. 2 of the supplemental information http://www.atmos-chem-phys.net/8/2039/2008/ acp-8-2039-2008-supplement.pdf.

\subsection{Aerosol measurements}

The aerosol composition, size, and number concentrations were quantified during the experiments with an Aerosol Mass Spectrometer (AMS) equipped with a quadrupole mass detector (Aerodyne Research Inc.), which has been described in previous publications (Allan, et al., 2004; Jayne, et al., 2000; Jimenez, et al., 2003). In summary, particles are sampled through a critical orifice and aerodynamic lens system, which collimates the particles and accelerates them into the time of flight region. The velocity, related to the particle size, can be calculated from the time needed to reach a heated surface from a chopper located downstream of the inlet. Particles are then impacted and vaporized on a heated surface $(\sim 580 \mathrm{C})$, ionized by electron impact (EI, $70 \mathrm{ev})$ and the resultant fragments carried into a quadrupole mass spectrometer for mass analysis. The AMS is capable of detecting single 

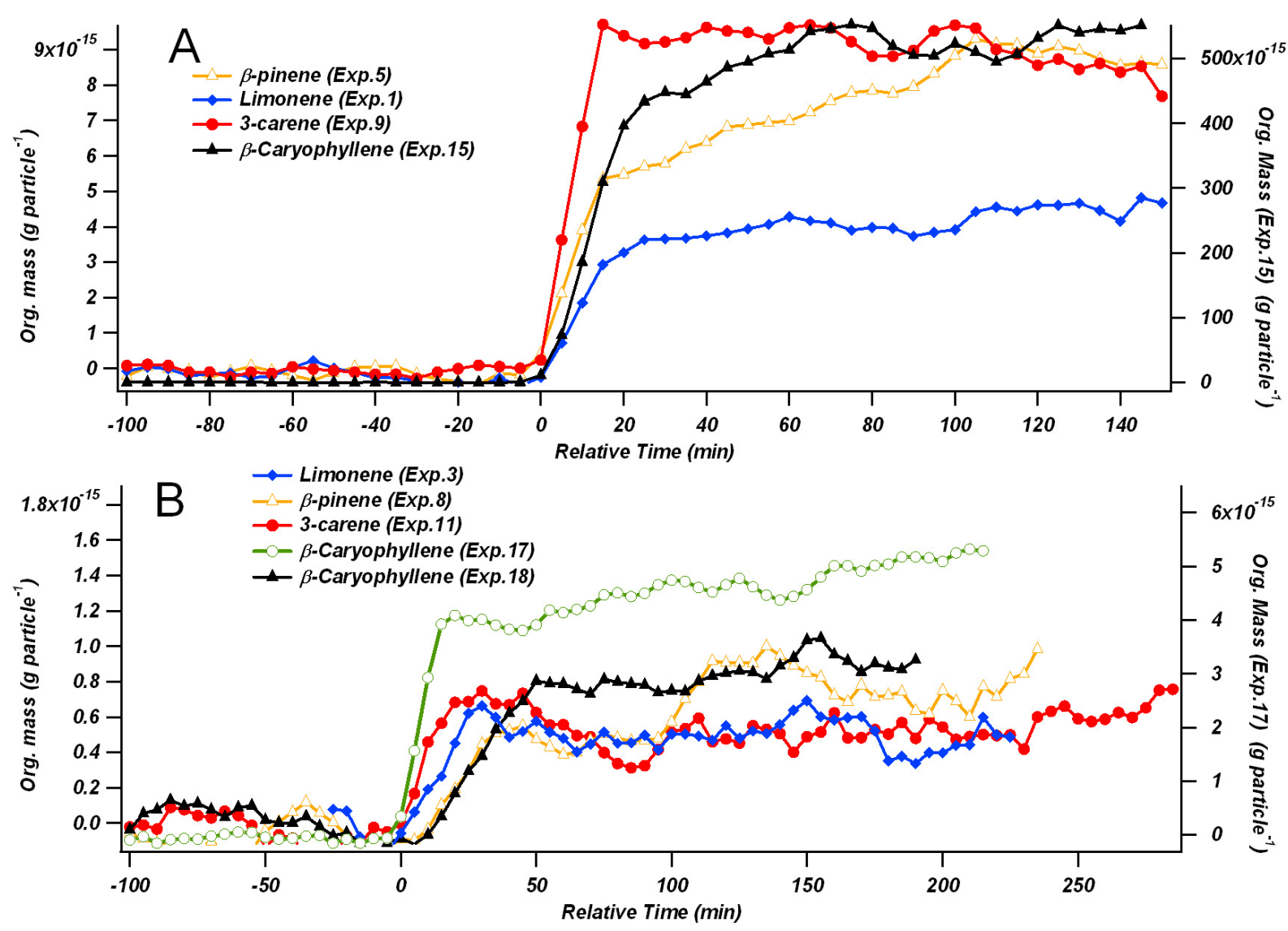

Fig. 2. Time dependent normalized organic mass (per particle) for selected experiments.

particle events for particles which contain sufficient mass ( $\sim 300 \mathrm{~nm} \mathrm{NH} \mathrm{NO}_{3}$ ) (Jayne, et al., 2000). Initial aerosol diameters greater than $300 \mathrm{~nm}$ were deliberately chosen to take advantage of the efficient single particle detection in this size regime. Although the most highly acidic aerosols in the troposphere may be nucleation mode nano-particles, subsequent coagulation/condensation can lead to fresh acidities in the few hundred nano-meter range. From an experimental point of view, the larger particles enable the single particle detection and chemical composition detection with the AMS. The AMS was operated with a time resolution of $5 \mathrm{~min}$, and sampled continuously for the length of each experiment (2.5$3 \mathrm{~h})$.

\section{Results and discussion}

Twenty-one experiments were performed under acidic particle conditions which were controlled by varying the relative humidity within the chamber. A summary of the results of uptake for each experiment is given as an organic mass concentration $\left(\mu \mathrm{g} \mathrm{m}^{-3}\right)$ in Table 2 , representing the maximum organic mass observed. The organic and inorganic mass was calculated based on the algorithm of (Allan, et al., 2004). Or- ganic material is added to the initial acidic seed particles in all cases, although to varying degrees, where the maximum organic mass loading ranged from $1-546 \mu \mathrm{g} \mathrm{m}^{-3}$ and corresponded to a maximum $\mathrm{SO}_{4}$ seed mass of 47.7-137.2 $\mu \mathrm{g}$ $\mathrm{m}^{-3}$. The time dependent mass loading curves were approximately the same for all compounds during this study and is given in Fig. 1 for a typical experiment. From Fig. 1 it is evident that the onset of organic uptake occurs very soon after the addition of the terpenoid species (denoted as $t=0$ ), and the maximum in the organic mass was usually achieved within the first 20-50 min of each experiment. This suggests that the uptake mechanism is rather fast. However, the time dependent mass loading, although useful as an indicator of uptake, is complicated by particle wall losses and the ensuing decrease of total organic and inorganic mass from $t=0$. This obscurity is removed by normalizing the mass concentrations $\left(\mu \mathrm{g} \mathrm{m}^{-3}\right)$ by the number concentrations $\left(\mathrm{cm}^{-3}\right)$ of the approximately mono-disperse aerosols. The result is the mass on a per particle basis $\left(\mathrm{g}\right.$ particle ${ }^{-1}$ ), given in Table 2 and reported as the value at the end of each experiment. The time dependent normalized organic mass for selected experiments are shown in Fig. 2. The normalized organic mass at the end of each experiment was highly variable, ranging 
Table 2. Measured organic mass uptake and calculated uptake parameters.

\begin{tabular}{|c|c|c|c|c|c|c|c|c|}
\hline Exp No. & Gas Phase Species & $\begin{array}{l}\text { Org Mass }^{\mathrm{a}} \\
\left(\mu \mathrm{g} \mathrm{m}^{-3}\right)\end{array}$ & $\begin{array}{l}\mathrm{SO}_{4} \mathrm{Mass}^{\mathrm{a}} \\
\left(\mu \mathrm{g} \mathrm{m}^{-3}\right)\end{array}$ & $\begin{array}{l}\text { Org/ part. }{ }^{\mathrm{b}}(\mathrm{g}) \times 10^{16} \\
( \pm \sigma)\end{array}$ & $\begin{array}{l}\mathrm{SO}_{4} / \text { part }^{\mathrm{c}}(\mathrm{g}) \times 10^{16} \\
( \pm \sigma)\end{array}$ & $\begin{array}{l}\mathrm{K}_{p, \text { eff }}^{\mathrm{d}}\left(\mathrm{m}^{3} \mu \mathrm{g}^{-1}\right) \times 10^{6} \\
( \pm \sigma)\end{array}$ & $\begin{array}{l}\alpha^{\mathrm{e}} \times 10^{5} \\
( \pm \sigma)\end{array}$ & $\begin{array}{l}\gamma^{\mathrm{f}} \times 10^{7} \\
( \pm \sigma)\end{array}$ \\
\hline 1 & Limonene & 5.0 & 60.6 & $41.3(4.6)$ & $377.6(20.0)$ & $4.3(1.1)$ & $2.6(1.3)$ & $6.6(3.0)$ \\
\hline 2 & Limonene & 4.9 & 137.2 & $25.0(4.1)$ & $678.8(24.0)$ & $12.3(7.5)$ & $5.4(2.4)$ & $36.5(16.6)$ \\
\hline 3 & Limonene & 1.25 & 76.8 & $5.0(3.5)$ & $447.6(32.7)$ & $1.5(1.0)$ & $0.9(0.6)$ & - \\
\hline 4 & Limonene & 1.0 & 49.0 & $2.4(4.7)$ & $661.9(33.0)$ & $0.61(1.0)$ & - & - \\
\hline 5 & $\beta$-pinene & 9.7 & 116.8 & $81.5(9.0)$ & $589.3(16.6)$ & $8.7(1.4)$ & $4.1(1.9)$ & $45.5(20.4)$ \\
\hline 6 & $\beta$-pinene & 1.29 & 51.6 & $11.5(2.0)$ & $427.1(28.3)$ & $2.0(0.57)$ & $0.30(0.16)$ & $0.87(0.49)$ \\
\hline 7 & $\beta$-pinene & 0.77 & 77.7 & $3.2(1.3)$ & $371.4(27.2)$ & $0.4(0.13)$ & $0.11(0.07)$ & $1.1(0.56)$ \\
\hline 8 & $\beta$-pinene & 1.2 & 60.0 & $7.4(1.8)$ & $301.8(18.1)$ & $1.4(0.4)$ & $0.12(0.06)$ & $1.1(0.53)$ \\
\hline 9 & 3-Carene & 23.6 & 100.2 & $91.7(5.5)$ & $408.0(21.0)$ & $35.5(6.2)$ & $12.6(5.8)$ & - \\
\hline 10 & 3-Carene & 2.8 & 47.7 & $7.3(5.8)$ & $387.0(26.4)$ & $2.9(2.0)$ & $1.6(0.9)$ & - \\
\hline 11 & 3-Carene & 2.6 & 94.0 & $5.4(1.7)$ & $281.0(18.0)$ & $2.7(1.2)$ & $0.28(0.16)$ & $1.1(0.50)$ \\
\hline 12 & Linalool & 63.3 & 59.7 & $456.8(26.5)$ & $476.8(20.4)$ & $1161(282)$ & $881(403)$ & - \\
\hline 13 & Linalool & 0.99 & 57.9 & $6.4(4.1)$ & $421.2(25.4)$ & $4.3(1.6)$ & $0.71(0.38)$ & $4.4(2.0)$ \\
\hline 14 & Geraniol & 21.9 & 80.8 & $104.4(7.3)$ & $345.8(32.4)$ & $1260(216)$ & 435 (196) & 255.7 (198) \\
\hline 15 & $\beta$-Caryophyllene & 546 & 79.6 & $5305(289)$ & $316.2(11.8)$ & 761.8 (130) & $2568(1600)$ & 739 (432) \\
\hline 16 & $\beta$-Caryophyllene & 69.4 & 65.0 & $849.1(61.8)$ & 388.7 (15.9) & $774.1(150)$ & $422(212)$ & $980(550)$ \\
\hline 17 & $\beta$-Caryophyllene & 7.6 & 79.1 & $49.0(3.6)$ & $369.6(25.1)$ & $58.1(9.6)$ & $12(6.5)$ & 41.7 (18.7) \\
\hline 18 & $\beta$-Caryophyllene & 1.5 & 77.4 & $8.7(3.1)$ & $437.5(23.8)$ & $10.5(2.1)$ & $1.1(0.55)$ & $6.0(2.9)$ \\
\hline 19 & $\alpha$-Humulene & 114.8 & 70.1 & $1393(89.0)$ & $452.3(30.6)$ & $810.3(144.9)$ & 535 (247) & - \\
\hline 20 & $\alpha$-Humulene & 1.1 & 72.7 & $4.9(1.1)$ & $351.5(11.9)$ & $1.8(0.7)$ & - & $8.7(3.9)$ \\
\hline 21 & Nerolidol & 13.7 & 52.6 & $82.7(7.4)$ & $417.8(27.1)$ & $34.2(6.7)$ & $17.3(10)$ & - \\
\hline
\end{tabular}

a Maximum mass as measured by the Q-AMS, neglecting particle wall losses.

${ }^{b}$ Organic mass normalized by AMS number concentration, near the end of the experiment (mean over the last $30 \mathrm{~min}$ ).

c Sulfate mass normalized by AMS number concentration at the end of the experiment, where no decrease in sulfate mass was observed. Where a decrease in $\mathrm{SO}_{4}$ per particle was observed a value prior to gas phase addition is reported.

$\mathrm{d}$ Assuming a near steady state was reached at the end of the initial fast uptake.

e Assuming uptake is controlled by mass accommodation in the fast initial phase (i.e.: $\gamma \sim \alpha$ ).

${ }^{\mathrm{f}}$ Calculated from the slow increase in organic mass after an initial fast uptake. A slow increase in organic mass per particle was not always observed (refer to text).

from $2.4 \times 10^{-16}-5.31 \times 10^{-13} \mathrm{~g}$ particle ${ }^{-1}$ and was dependent upon relative humidity (RH); the largest uptake being observed under the lowest RH conditions (see next section). It is important to note that previous experiments with a similar BVOC, under comparable conditions but with entirely neutral aerosols, has shown that a negligibly small uptake occurs (Liggio and Li, 2006b ). In addition, the AMS spectra of the pure BVOCs are very different than those observed from the acidic aerosols in this study (see Sect. 3.2). There was also a significant difference in the normalized organic mass between classes of biogenic compounds. The mass taken up for simple monoterpenes such as limonene, $\beta$-pinene and 3 -carene under similarly acidic conditions was appreciably less than that of oxygenated monoterpenes or sesquiterpenes. This likely reflects the large differences between the vapor pressures of such compounds, and ultimately the accommodation of gases to the particle surface. Furthermore, the time dependent normalized mass curves in Fig. 2 typically exhibit a fast initial uptake followed by a slower increase in mass for the remainder of the experiment. This suggests the existence of multiple reactions/equilibria and is discussed further in the following sections.

\subsection{Effect of relative humidity and acidity}

Although experiments were conducted with acidic aerosols to varying degrees (Table 1), even aerosols with the weakest acidity contained substantial acidity ( $\mathrm{pH} \sim-1.17)$ likely sufficient for acid catalysis to occur were it an important aspect of the reactions. Thus, the changes in uptake due to the changes in the aerosol acidity in these experiments were likely not large. In comparison, the effect of relative humidity $(\mathrm{RH})$ is more pronounced. Significant differences in the magnitude of organic uptake were observed by varying the RH within the chamber, regardless of the species studied. These results are highlighted in Fig. 2. Increasing the RH from less than $5 \%$ (Fig. 2a) to $20-73 \%$ (Fig. 2b), and thus more realistic atmospheric RH conditions, reduced the normalized organic mass uptake, often by an order of magnitude, but still indicates that this process occurs under atmospheric RH conditions. The reduced uptake at increased RH (and thus increased aerosol liquid water content) also suggests that the solubility of the terpenoids plays an important role; the solubility of the hydrocarbons is typically small in water, but can be significantly enhanced in acidic solutions. Increasing the RH, thus increasing water content on the particles, in the experiments likely has the effect of decreasing the terpenoid 

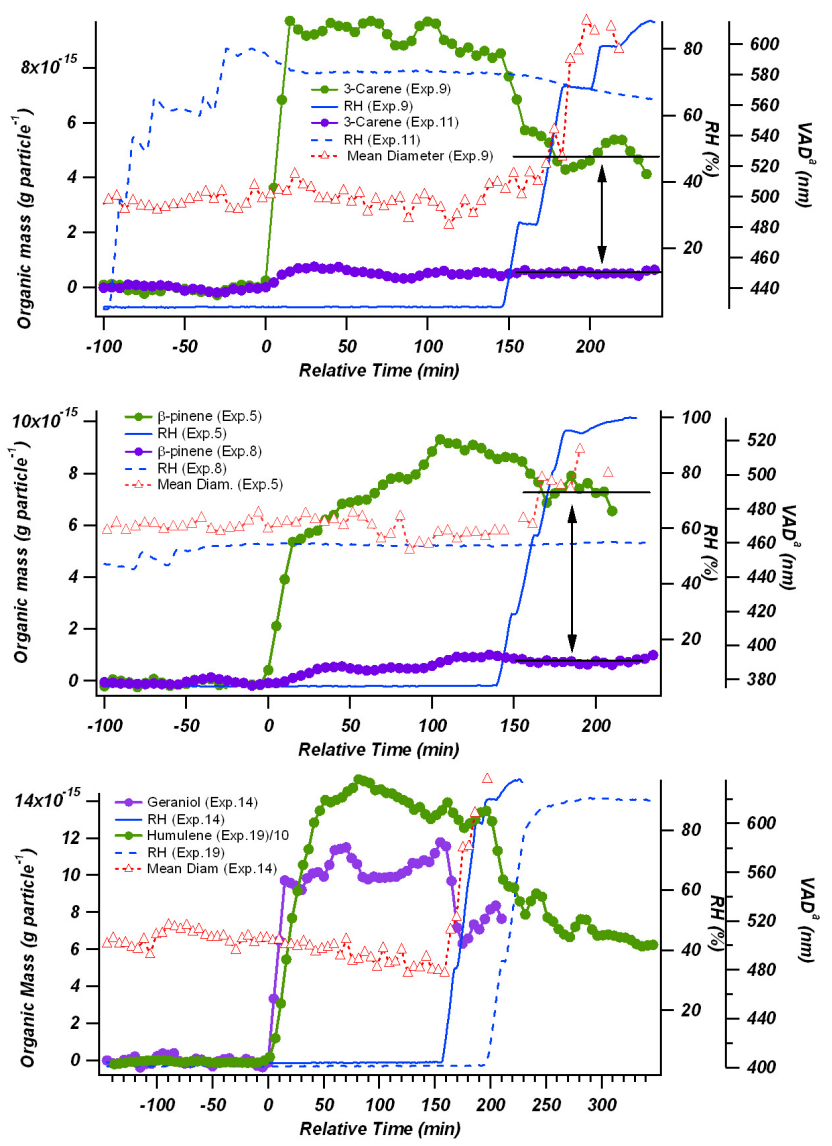

Fig. 3. Effect of increasing RH after initial uptake on the per particle normalized organic mass for selected experiments. (a) Vacuum aerodynamic diameter.

solubility and limiting the amount available for further reactive transformation in the particles which may be acid catalyzed. A secondary effect of increased RH is the dilution of acidity in the particles, although in these studies the particle acidities were not entirely controlled without changing the liquid water content, and thus this secondary effect could not be observed.

The importance of RH and solubility is also highlighted in several experiments where the RH was increased after reactive uptake had already occurred (Exp. 5, 9, 14 and 19), the results of which are shown in Fig. 3. The equivalent experiments utilizing 3 -carene and $\beta$-pinene at fairly high $\mathrm{RH}$ from the start of each experiment is also shown in the figure for comparison. As illustrated in Fig. 3, increasing the $\mathrm{RH}$ after uptake has occurred immediately reduces the organic mass per particle in all cases. This is evidence that a type of equilibrium must exist between reaction products and the original terpenoid species. Increasing the $\mathrm{RH}$, and hence the particle water content, likely decreases the solubility of the parent terpenoid and shifts the equilibrium from aerosol phase product $(p)$ to gas-phase species $(g)$ as depicted below.

$$
\begin{gathered}
\text { Terpene }_{(g)} \rightleftharpoons \text { Terpene }_{(l)} \rightleftharpoons \text { ReactionProduct }_{(p)} \\
\downarrow \\
\text { ReactionProduct }_{(p 2)}
\end{gathered}
$$

Slight increases in the gas-phase concentration measurements upon increasing the RH were observed (Fig. 2 - Supporting information http://www.atmos-chem-phys.net/ 8/2039/2008/acp-8-2039-2008-supplement.pdf). However, the response of the PTR-MS is sensitive to increases in RH (by increasing available protons). Such a small increase in the gas phase (ppb) is not discernable from the results of this effect and are likely not observable over the ppm levels which are initially present. The reverse reaction in Eq. (1) above is obviously driven by the increase in particle water content. However, data clearly show that the reverse reaction in Eq. (1) is not complete, and as indicated by Eq. (1) that some of the dissolved terpenoids in particles probably end up in the reaction product $(p 2)$ which is not reversible. This is demonstrated by the clear difference in the aerosol organic mass uptake of experiments of different RH in Fig. 3. Experiment 8 ( $\beta$-pinene, $54 \% \mathrm{RH}$ ) and 11 (3-carene, $73 \% \mathrm{RH})$ were conducted as high RH cases to show low organic uptake as a baseline. Experiment 5 ( $\beta$-pinene) and 9 (3-carene) were conducted with RH which began low (3.3\% and $2.4 \%$, respectively), leading to high initial uptake. The RH was then increased (eventually $>80 \%$ ) approximately $150 \mathrm{~min}$ after the gas exposure of the particle and the initial uptake took place (Fig. 3). Although the organic mass decreased significantly in both cases upon the RH increase, it did not reach the low organic mass in the baseline Exp. 8 and 11, respectively, at the same RH. The difference is represented by the arrows in Fig. 3, and implies that a portion of the uptake products, prior to the RH increase, is formed via irreversible reactions, likely in the liquid phase as shown in Eq. (1) ( $p 2)$. An increase in particle diameter (Fig. 3) is also observed immediately upon the increase of the $\mathrm{RH}$, suggesting that water is fairly well mixed within the particle, since a relatively hydrophobic organic layer is unlikely to take up such significant amount of water. This removes the possibility that the elevated organic mass (after increasing the $\mathrm{RH}$ ) compared to the base case was caused by a limitation of water uptake by the organics. Regardless, there was likely sufficient time for diffusion through the organic layer if necessary. It is likely that these irreversible reactions occur continuously throughout the experiment but become increasingly important during the slow increase in organic mass observed for many experiments, after an initial steady state has almost been reached (Fig. 2). These irreversible reactions act to slowly shift the equilibrium of Eq. (1) to the right. The nature of these reversible and irreversible products is discussed below. 

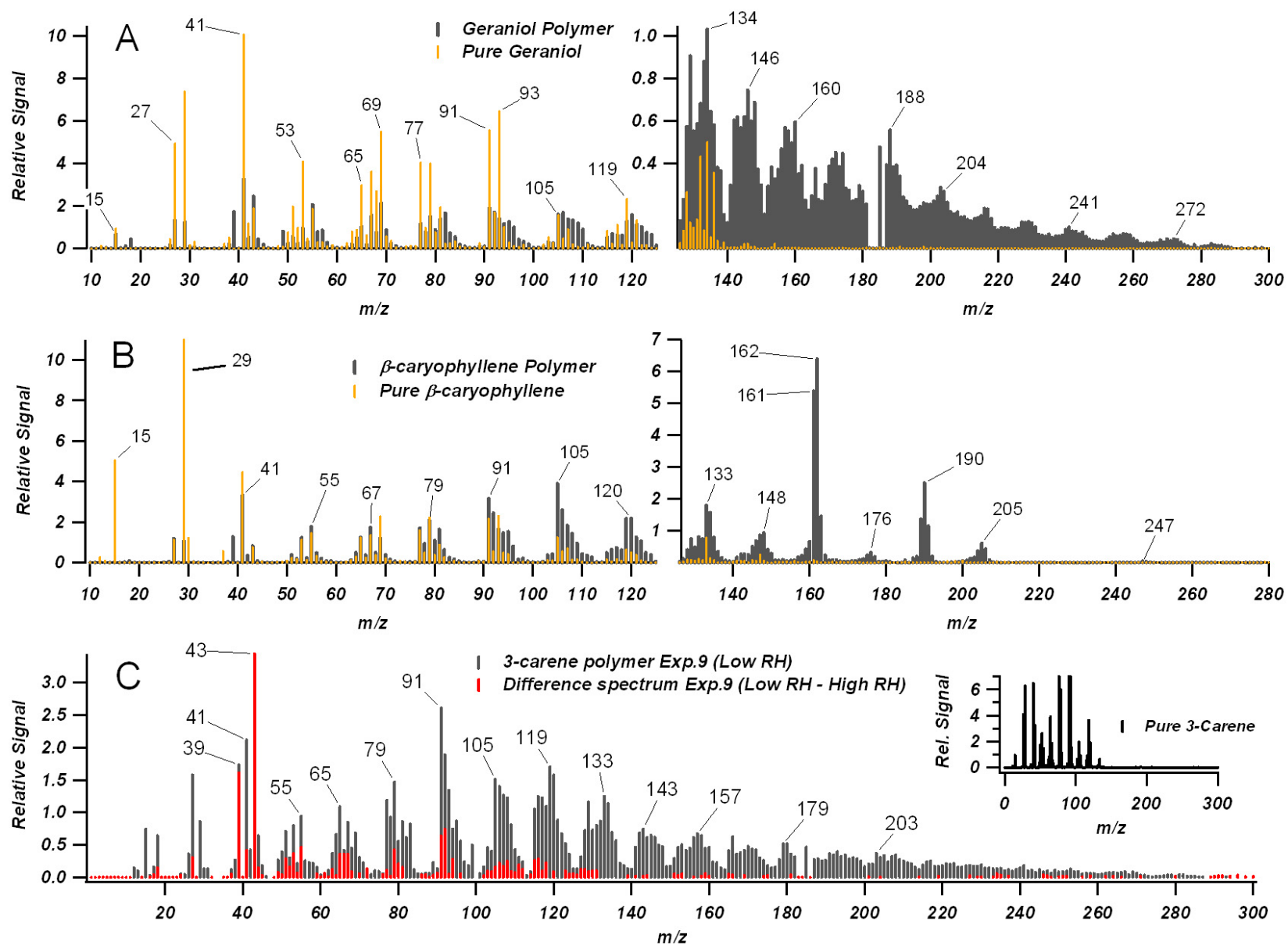

Fig. 4. (a and b) Aerosol mass spectra of reaction products collected near the end of a given experiment, compared to the AMS derived spectra of the pure compound. (c) Aerosol spectra for 3-carene reaction products of Exp. 9, at low RH compared to the relative spectra of the mass spectral difference (Low RH, Exp. 9-High RH, Exp. 9) (C-inset). AMS derived spectra of pure 3-carene.

\subsection{Aerosol spectra, reaction mechanisms and reversibility}

It is probable that the uptake of organic material in this study has arisen from heterogeneous reactions subsequent to physical absorption and solubility. Firstly, a pure physical absorption or adsorption to the aerosol phase, based on the theories of Pankow (Pankow, 1994), could not account for the amount of mass taken up in these experiments. The high vapor pressures associated with these compounds preclude these physical processes from being a significant contributor, assuming that the species is not transformed to a low volatility product as would be the case in a neutral aerosol. Although adsorption/absorption coefficients for these volatile terpenes have not been studied, partition coefficients (absorption/adsorption) for similarly volatile compounds such as low MW aldehydes are estimated to be less than $10^{-10} \mathrm{~m}^{3} \mu \mathrm{g}$, far less than what has been observed in this study (Table 2). Secondly, the observed aerosol mass spectra are consistent with heterogeneous products of low volatility. Typical aerosol mass spectra for monoterpenes, oxygenated mono-terpenes, and sesquiterpenes collected near the end of a given experiment are presented in Fig. 4 and 5. Numerous $m / z$ fragments appear in the spectra of Fig. 4 and Fig. 5 which are far greater than the molecular weight of the parent species $(136 \mathrm{~g} / \mathrm{mol}, 154 \mathrm{~g} / \mathrm{mol}, 204 \mathrm{~g} / \mathrm{mol})$, up to the mass limit of the AMS $(m / z$ 300), despite the fact that the harsh ionization and heating of the AMS tends to result in smaller fragments.

Furthermore, the reaction product spectra can be compared with the AMS derived spectra of the pure liquid terpenes/sesquiterpenes. AMS spectra of the pure compounds were generated by rapidly heating and cooling the pure liquids, resulting in sufficient nucleation and growth into droplets, which could be measured with the AMS. These results are also shown in Fig. 4 and Fig. 5. It is clear from these figures that the AMS spectra for the studied compounds are in all cases very different than the spectra of the pure organic aerosol products. Pure compound spectra do not contain any fragments greater than the parent molecular weight, in stark contrast to the reaction product spectra. In addition, the pure spectra are quite different in the low mass range. This is clear 

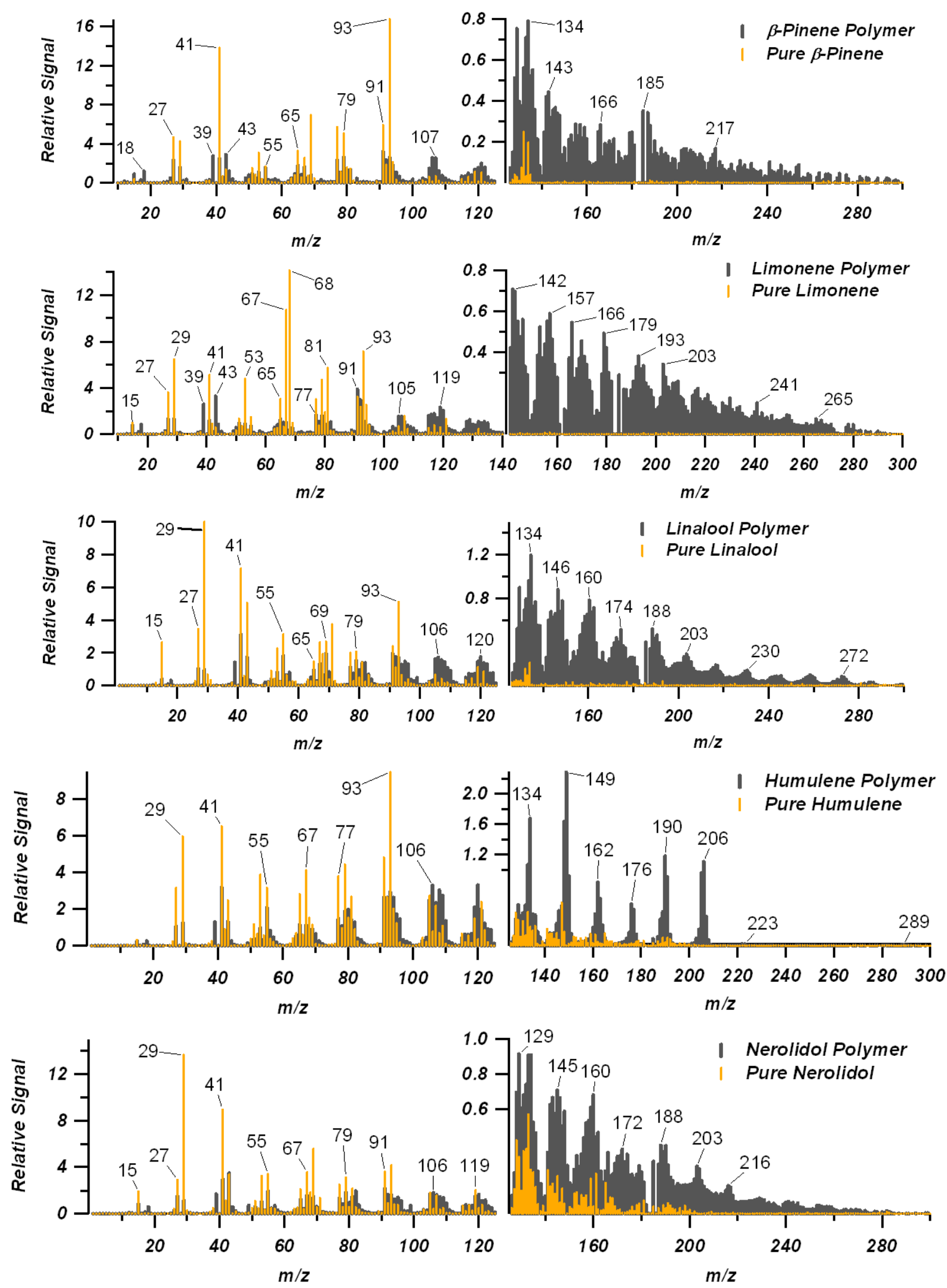

Fig. 5. Aerosol mass spectra of reaction products collected near the end of a given experiment, compared to the AMS derived spectra of the pure compound. 

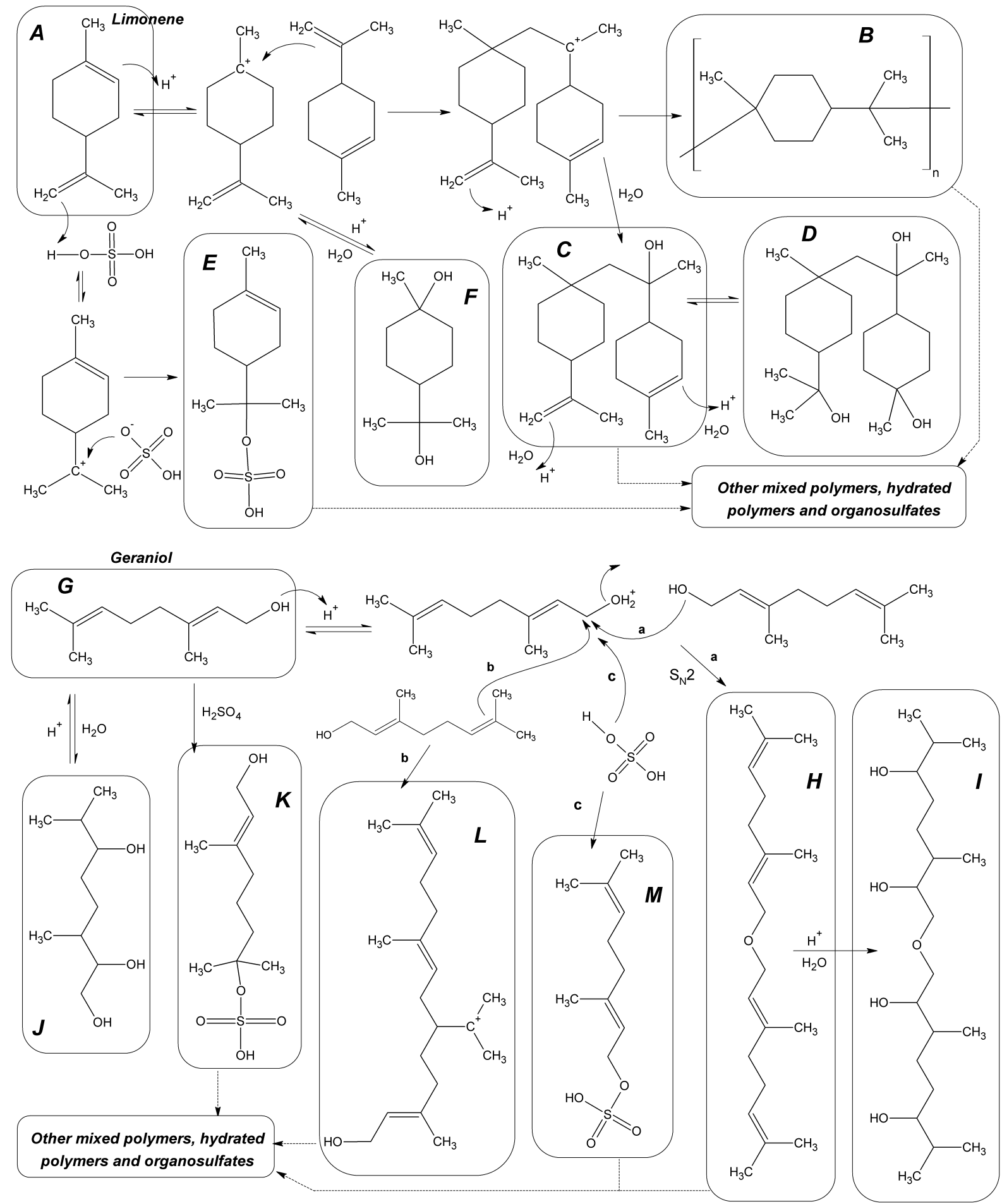

Fig. 6. Potential mechanism leading to heterogeneous products of limonene and geraniol. Mechanisms shown do not represent all possible reactions.

evidence that heterogeneous reactions were undoubtedly responsible for the uptake that was observed.

There is evidence that more than one type of reaction mechanism was at play, leading to different types of reac- tion products, some of which are reversible in response to changes in RH that probably changed the aerosol water content, while others are not. A representation of possible pathways for the direct uptake of limonene and geraniol is given 


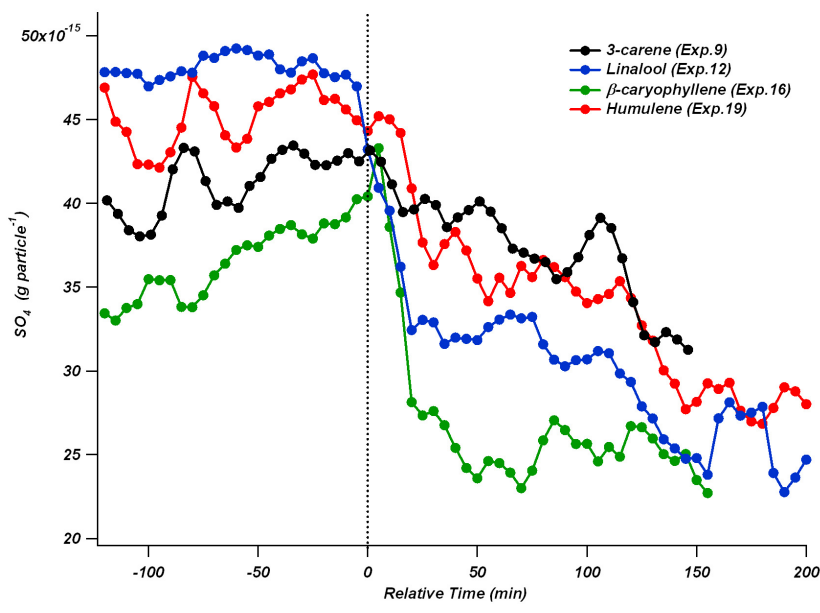

Fig. 7. Decrease in the AMS measured $\mathrm{SO}_{4}$ (per particle) after the addition of the biogenic gas $($ time $=0)$ for selected experiments, suggesting the formation of organosulfates.

in Fig. 6. It should be noted that these mechanisms do not represent all possible pathways or chemical structures, nor do they take into account the stability of products. In fact there are likely many other reaction pathways, some of which may be more energetically favorable than what has been presented. Given the presence of olefins in the starting compounds, the observed large $m / z$ fragments, and the aerosol acidity, it is very likely that a cationic polymerization has occurred, of which the final structure and size may be somewhat unclear, but likely resembles the structures in Fig. 6 . As noted previously (Liggio, et al., 2007), the uptake of isoprene and $\alpha$-pinene to acidic aerosols proceeds primarily via a cationic polymerization mechanism. Similarly, the uptake of the non-oxygenated monoterpenes and sesquiterpenes in the present study likely also proceed via this route. As exemplified in Fig. 6 for the uptake of limonene by cationic polymerization, the initial protonation (regardless of the position) under acidic conditions can lead to complex polymeric structures such as B (Fig. 6) (or others), where polymers are terminated by $\mathrm{H}_{2} \mathrm{O}(\mathrm{C})$ and may be further hydrated, either partially or fully (D). Fragments possibly associated with this mechanism, and observable in the mass spectrum, indicate that polymerization of at least 2 limonene units had occurred, although the mass range of the AMS (300) is limiting. Numerous other polymer orientations (too many to show), are possible from different combinations of ring cleavage and further polymerization. As a result of potential ring cleavage, and since all non-oxygenated monoterpenes have the same molecular weight $\left(\mathrm{C}_{10} \mathrm{H}_{16}\right)$ and are reactive with respect to the olefin bonds present, they are expected to undergo similar polymerization reaction mechanisms, potentially leading to similar products. Due to the intense heating and ionization associated with the AMS, one might expect these polymers to break down similarly, and may explain the similarity in the spectra of limonene (Fig. 5), 3-carene (Fig. 4C), $\beta$-pinene (Fig. 5) and $\alpha$-pinene (Liggio, et al., 2007).

Although a similar mechanism is likely to occur for the non-oxygenated sesquiterpenes, the obtained spectrum (Fig. 4b) is largely skewed towards higher $m / z$ fragments, reflecting the larger molecules of the sesquiterpenes with the additional $\mathrm{C}_{5} \mathrm{H}_{8}$ functional group compared to the terpenes. Nonetheless, as an example, the mass spectrum of $\beta$-caryophyllene products is again consistent with a cationic polymerization mechanism. Given that the parent $m / z$ of $\beta$-caryophyllene is 204 , the unusually large abundance of $\mathrm{m} / \mathrm{z} 205$ compared to that of the pure compound specta (Fig. 4b) implies that initial protonation leading to a carbocation $(\mathrm{M}+1)$ and hence further polymerization has occurred, while other polymer fragments are also observable in the mass spectrum.

\subsection{Esters and ethers in aerosols}

Oxygenated monoterpenes (or sesquiterpenes) may take an additional potential route to oligomerization products; the same conditions which foster cationic polymerization are conducive to ester/ether formation. A generalized mechanism for geraniol is presented in Fig. 6 to illustrate this point. In addition to carbocation formation from double bonds, protonation of the alcohol group on the geraniol molecule can also occur. This results in the attack of an electrophillic $\mathrm{OH}$ group as shown in Fig. 6 via an $\mathrm{S}_{\mathrm{N}} 2$ mechanism leading to the ether product $\mathrm{H}$, which can be further hydrated partially or fully (I). Ether formation under these conditions (acidic and $<150 \mathrm{C}$ ) is favored over the $\mathrm{E}_{1}$ elimination (Wade, 2003) which would lead to a dehydration of the alcohol group. Attack of an electrophillic olefin at the same position via path b (L) may also occur and would lead to similar products as the reaction of non-oxygenated monoterpenes. The mass spectrum of geraniol products is in fact different than other monoterpenes (e.g. limonene, Fig. 5), being slightly shifted to larger $m / z$.

In addition to organic ethers, inorganic esters may also arise as illustrated in the mechanisms for limonene and geraniol (Fig. 6). The mechanisms of Fig. 6, leading to organo-sulfates, are slightly different than reported previously for carbonyl containing species (Liggio and Li, 2006a). In that case, nucleophilic attack of $\mathrm{SO}_{4}{ }^{2-}$ was required, however, under many conditions sulphate is a weak nucleophile. Hence steps A-E and G-K in Fig. 6 may be somewhat less favorable, although they may occur when few other nucleophiles are present. A more favorable scenario is the addition of sulfuric acid to olefins leading directly to organo-sulfates via attack of the olenific bond ( $\mathrm{E}$ and $\mathrm{K})$; a reaction which is known to occur for most alkenes (Wade, 2003). Evidence for the existence of organosulfates in this study is based upon a decrease in the measured $\mathrm{SO}_{4}$ per particle after the addition of the hydrocarbons, as shown in Fig. 7 for several experiments. A decrease in the measured $\mathrm{SO}_{4}$ during the 
reactive uptake of a biogenic oxidation product (pinonaldehyde) has also been attributed to the formation of organosulfates previously (Liggio and $\mathrm{Li}, 2006 \mathrm{a}$ ). This decrease in $\mathrm{SO}_{4}$ was most evident in experiments with the lowest relative humidity which also resulted in the highest proton concentrations in the aerosols. Organosulfates may also form during less acidic experiments; however, the decrease in $\mathrm{SO}_{4}$ is obscured by the uncertainty in the $\mathrm{SO}_{4}$ per particle measurement. The formation of organosulfates in this study is consistent with recent evidence of their formation in other acidic aerosol experiments, and their detection in the ambient atmosphere (Iinuma, et al., 2007a; Iinuma, et al., 2007b; Surratt, et al., 2007). Currently, AMS spectral evidence for any organosulfate products is not definitive given that most fragments derived would have the same nominal mass as any other heterogeneous reaction product fragment.

The proposed mechanisms are also consistent with the observed relationship between the normalized organic mass per particle and RH (Fig. 3). Typically, the addition of monomers to carbocations forming polymers, organic ether formation and the addition of sulfuric acid to alkenes are irreversible (at ambient temperatures), as depicted in Fig. 6. Conversely, protonation of olefins and subsequent hydration is relatively fast and entirely reversible (Wade, 2003). Hence, it is likely that the irreversible reaction products of Fig. 3 are due to oligomerization or organosulfate formation, which is somewhat insensitive to increases in RH provided that sufficient acidity remains to catalyze reactions. Furthermore the rapid response to increases in RH (water content) is likely a result of the hydration of olefins and potentially the formation of the first generation hydrated terpenoid products depicted as $\mathrm{F}$ and $\mathrm{J}$ in Fig. 6. As noted above, the increase in the aqueous content of the aerosol would decrease the solubility of the terpenoid, thus shifting the equilibrium to the gas phase via Eq. (1). A comparison of the relative mass spectrum difference (difference before and after $\mathrm{H}_{2} \mathrm{O}$ addition of Exp. 9) with the relative spectrum at the end of a 3-carene experiment (Exp. 9) is given in Fig. 4c. The spectral difference represents the mass spectra of the organic material lost upon increasing the RH during Exp. 9. This spectrum is clearly composed of lower mass fragments, particularly when compared to the residual spectrum. This implies that a volatile species is lost, possibly 3-carene from the reversibly formed hydrated 3-carene. The difference spectrum in Fig. 4c is similar to the AMS spectrum of pure 3-carene (Inset, Fig. 4c), although the relative intensities are slightly different. Similarly, lower mass fragments are also observed in the difference spectra of Exp. 5, 14 and 19.

\subsection{Quantitative results}

\subsubsection{Steady state partitioning}

Under steady state conditions partitioning of gases to aerosols can be described by an effective partitioning coef- ficient $\left(K_{P, \text { eff }}\right)$ :

$K_{p, \text { eff }}=\frac{\left(C_{p} / C_{\mathrm{TSP}}\right)}{C_{g}}$

where $C_{p}$ represents the total organic mass derived from the studied species, regardless of its current form $\left(\mu \mathrm{g} \mathrm{m}^{-3}\right), C_{g}$ represents the concentration of the species in the gas-phase $\left(\mu \mathrm{g} \mathrm{m}^{-3}\right)$ and $C_{\mathrm{TSP}}$ represents the total suspended particle mass $\left(\mu \mathrm{g} \mathrm{m}^{-3}\right)$. Estimated $K_{P, \text { eff values during this study }}$ are given in Table 2. In most experiments a relatively fast initial uptake is observed, which as described above is attributed to a fast reversible process; possibly hydration. Based on the fast rate of the initial uptake compared to the slow organic increase afterwards, $K_{P \text {,eff }}$ can be approximated from the normalized organic mass after this initial period, assuming that a semi-steady state has been reached and irreversible liquid phase reactions do not control the overall organic mass uptake at this point. Although a steady state may not always be entirely achieved during these experiments due to the presence of liquid phase irreversible reactions, the additional mass added beyond the initial uptake is usually quite small, and thus $K_{p \text {,eff }}$ can be approximately determined. This estimation would only be applicable for the ambient atmosphere if a near steady state was actually achieved, similar to that observed in these experiments. Whether this steady state in ambient particles is ever achieved is unclear. The TSP mass used in the calculation was determined as the sum of the inorganic and organic mass during the same period. Estimated $K_{p \text {,eff values are highly variable, ranging from }}$ $0.4 \times 10^{-6}-1.3 \times 10^{-3} \mathrm{~m}^{3} \mu \mathrm{g}^{-1}$ depending on the RH or acidity; with the highest values for any given species observed at the lowest RH and hence highest acidity. This is consistent with a reversible hydration mechanism. Furthermore, $K_{p \text {, eff }}$ for the oxygenated monoterpenes or sequiterpenes were often several orders of magnitude higher than those for simple non-oxygenated monoterpenes. This may reflect the lower vapour pressures associated with sesquiterpenes or the increased solubility in acidic solution of oxygenated species. However, even the smallest $K_{p \text {,eff }}$ values (simple monoterpenes) are large when compared with other species which have experimental partition coefficients in a similar range (Chandramouli, et al., 2003) yet significantly lower vapour pressure than those compounds studied here. Although increased physical solubility can occur in acidic media, it is unlikely that this increase would span the several orders of magnitude required to explain the observations here. This suggests that the fast initial uptake and approximate steady state is not purely a physical process. Although the applicability of the TSP in these experiments to that of the ambient atmosphere may be limited to situations where aerosol acidities are high, the calculated $K_{p \text {,eff }}$ values are a first step in assessing the importance of this process. 


\subsubsection{Kinetics of uptake}

Conversely, the rapid initial increases in the organic mass per particle (Fig. 2) may be more appropriately described via uptake coefficients $(\gamma)$. Uptake coefficients have been shown previously to be useful in assessing the importance of oligomer formation under kinetic control (Liggio, et al., 2005), and are also presented in Table 2 for this study. The measured uptake coefficient is defined as the probability that a collision between a gas molecule and the aerosol surface will result in uptake, taking into account all aspects of the uptake process including diffusion, mass accommodation, solubility and reactivity. These processes can be decoupled, and formulated as individual resistances (ignoring surface reactions) which sum to the overall uptake coefficient as shown in Eq. (3) (Shi, et al., 1999),

$$
\frac{1}{\gamma}=\frac{1}{\Gamma_{\text {diff }}}+\frac{1}{\alpha}+\frac{1}{\Gamma_{b}}
$$

where $\Gamma_{\text {diff }}$ represents the effects of diffusion, $\alpha$ represents mass accommodation, and $\Gamma_{b}$ accounts for solubility and liquid phase reactivity. Given the particle diameters and estimated diffusion coefficients for terpenoids, the resistance to mass transfer due to diffusion $\left(1 / \Gamma_{\text {diff }}\right)$ can be estimated in the manner described by Shi, et al. (1999). The calculated diffusion resistance for these experiments was in the range of 0.86-1.45; significantly less than the smallest measured $1 / \gamma$ below $\left(10^{4}-10^{7}\right)$. Thus the $1 / \Gamma_{\text {diff }}$ term can be effectively ignored and Eq. (3a) becomes:

$$
\frac{1}{\gamma} \cong \frac{1}{\alpha}+\frac{1}{\Gamma_{b}}
$$

As noted previously, the mass uptake curves (Fig. 2) in most cases, can be described by a fast initial uptake followed by a slower uptake region. Accordingly, uptake coefficients may be determined for both regions. In the initial phase of fast uptake, the resistance to mass transfer is either due to mass accommodation $(\alpha)$ or hydration reactions (encompassed within $\Gamma_{b}$ ), while other irreversible reactions are assumed to contribute little, at least initially. Acid catalyzed hydration of alkenes is invariably a first order process with the olefin protonation being the rate determining step (Chwang, et al., 1977). First order rate constants for hydration of structurally similar compounds (in weaker acidic solutions) (Slebocka-Tilk et al., 1996) imply an olefin lifetime on the order of several seconds or less, with an effective steady state reached very quickly and favoring the protonated alkene. Given that the initial fast uptake phase takes as long as $20-40 \mathrm{~min}$ in some cases it is likely that the resistance to mass transfer is dominated by mass accommodation, i.e.:

$$
\left(\frac{1}{\gamma}\right)_{\text {initial }} \approx \frac{1}{\alpha}
$$

This is also consistent with terpenoids having lower vapor pressures exhibiting a larger initial uptake, despite the fact that their reactivity with respect to hydration were likely similar. Thus, measured uptake coefficients in this region are more likely an estimation of the mass accommodation coefficient $(\alpha)$. The resistances to mass transfer for the second phase, characterized by a slow increase in the organic mass, is not so easily decoupled even though the curvature in Fig. 2 does indeed suggest that a change in the factors controlling the uptake has occurred, and thus Eq. (3b) still holds approximately true. Although this increase in organic mass is expected to be a result of irreversible reactions, it is not possible to determine if either of the $1 / \alpha$ or $1 / \Gamma_{b}$ resistance terms are controlling, or of similar magnitude. In principle, mass accommodation $(\alpha)$ could be reduced in this region as the surface characteristics of the particle change over time (become more organic). If $\alpha$ is not reduced, then the uptake coefficients calculated for this phase could represent $\Gamma_{b}$, controlled by reactivity. Uptake coefficients from the first phase as determined from Eq. $(3 \mathrm{c})\left(\gamma_{\text {initial }} \approx \alpha\right)$ are more likely applicable to freshly nucleated $\mathrm{H}_{2} \mathrm{SO}_{4}$ particles or pre-existing particles which have been freshly coated with $\mathrm{H}_{2} \mathrm{SO}_{4}$. On the other hand, uptake coefficients from the second region of Fig. 2 may be more applicable to aged aerosols.

Uptake coefficients are obtained by fitting a simple uptake model to the organic mass of the irreversible uptake region, which is shown for several experiments in Fig. 8. The change in the normalized organic mass $\left(m_{\text {org }}\right)$ added to an aerosol exposed to gaseous organic can be described by,

$\frac{d m_{\mathrm{org}}}{d t}=\gamma \pi a^{2}<c>C_{g}$

where $a,\left\langle c>\right.$ and $C_{g}$ represent the particle radius, mean molecular speed, and gas phase concentration respectively. Since in these experiments the addition of organic mass to the aerosol results in a negligible increase in particle radius $(<1 \%)$ from an initial seed diameter of greater than $300 \mathrm{~nm}$, the radius is treated as a constant. Integration of Eq. 4 from $m=m_{0}$ to $m=m_{\text {org }}$ and $t=t_{0}$ to $t$ where $m_{0}$ is the initial organic mass at the beginning of each uptake region and $t_{0}$ is the corresponding time, yields an equation representing the mass uptake as a function of time

$M_{\text {org }}=k t+C$

where $k=\gamma \pi a^{2}<c>\mathrm{C}_{g}$ and $\mathrm{C}=-\mathrm{kt}_{0}+m_{0}$. The uptake coefficient $\gamma$ is derived from $k$ assuming all other parameters are constant. The density of an appropriate $\mathrm{H}_{2} \mathrm{SO}_{4}$ solution was used to estimate the mobility diameter and hence $a$ in Eq. 4. For cases where a very high organic mass uptake is observed (Exp. 15 and 16), a similarly derived equation describing the uptake, but accounting for an increasing diameter, is fit to the mass data;

$m_{\text {org }}=\left(\frac{j t-i}{h}\right)^{3}-f$

where 
$j=\frac{3 \gamma<c>}{4 \rho} i=\frac{3 \gamma<c>C_{g} t_{0}}{4 \rho}+3\left(\frac{3 m_{0}}{4 \pi \rho}+a_{0}^{3}\right)^{\frac{1}{3}}$

$h=3\left(\frac{3}{4 \pi \rho}\right)^{\frac{1}{3}} f=\frac{4 \pi \rho a_{o}^{3}}{3}$

where $a_{0}$ and $\rho$ represent the initial seed aerosol radius and the density of the organic mass $\left(1.4 \mathrm{~g} \mathrm{~cm}^{-3}\right)$. This uptake model has been described previously (Liggio and Li, 2006b). The uptake coefficient $(\gamma)$ is obtained from the parameter $j$. For several experiments a slow increase in the organic mass per particle after the initial uptake phase is not observed, and thus uptake coefficients for this region were not determined. This may be a result of changes in RH caused by fluctuations in temperature (not controlled), which alters the aforementioned equilibrium and obscures a typically small irreversible uptake. It may also be the result of a drastically reduced mass accommodation coefficient $(\alpha)$ caused by significant initial uptake of organic mass in some cases.

The relative uncertainty in the $k$ parameter of Eq. 5 or the $j$ parameter of Eq 6 derived from the fitting procedures ranged from 4 to $35 \%$. This uncertainty, together with those associated with the assumed density, $C_{g}$ and estimated mobility diameter, results in an overall uncertainty in the uptake coefficients $\gamma$ of approximately 52\% (averaged over all $\gamma$ ). Another uncertainty is associated with potential for organosulfate formation. Given that for those experiments in Table 3 a decrease in $\mathrm{SO}_{4}$ was observed, it is possible that a portion of this $\mathrm{SO}_{4}$ loss was quantified as organic. Consequently, assuming a mass conservation, the total uptake of biogenic species and hence their uptake coefficients (and $K_{p \text {,eff }}$ may be somewhat lower than reported. Nonetheless, the derived uptake coefficients can serve as a useful first approximation for the overall importance of this process.

The derived uptake coefficients for both uptake regions $(\alpha$ or $\gamma)$ were highly variable $\left(\alpha \approx 1 \times 10^{-7}-1 \times 10^{-4}\right.$ and $\gamma \approx 1 \times 10^{-6}-2.5 \times 10^{-2}$ ) and are larger for low RH/high acidity experiments than those at higher RH. In all cases, $\alpha$ from the initial phase was at least an order of magnitude larger than $\gamma$ of the slower uptake region, implying that uptake on fresh acidic aerosol coatings is considerably faster than on a more aged particles. Furthermore, uptake coefficients $(\alpha$ or $\gamma)$ for oxygenated monoterpenes and sesquiterpenes were significantly larger than those for simple monoterpenes. Currently, there are no other measurements of reactive uptake coefficients or mass accommodation coefficients for these compounds on any surface type; however, the estimated coefficients for simple monoterpenes during the initial uptake are similar to those measured for the $\alpha$-pinene oxidation product, pinonaldehyde, under otherwise similar conditions (Liggio and $\mathrm{Li}, 2006 \mathrm{~b}$ ), while $\gamma$ of the slower uptake region are generally smaller than those of pinonaldehyde. The coefficients for oxygenated terpenes and sesquiterpenes are appreciably larger than those measured previously for pinonalde-
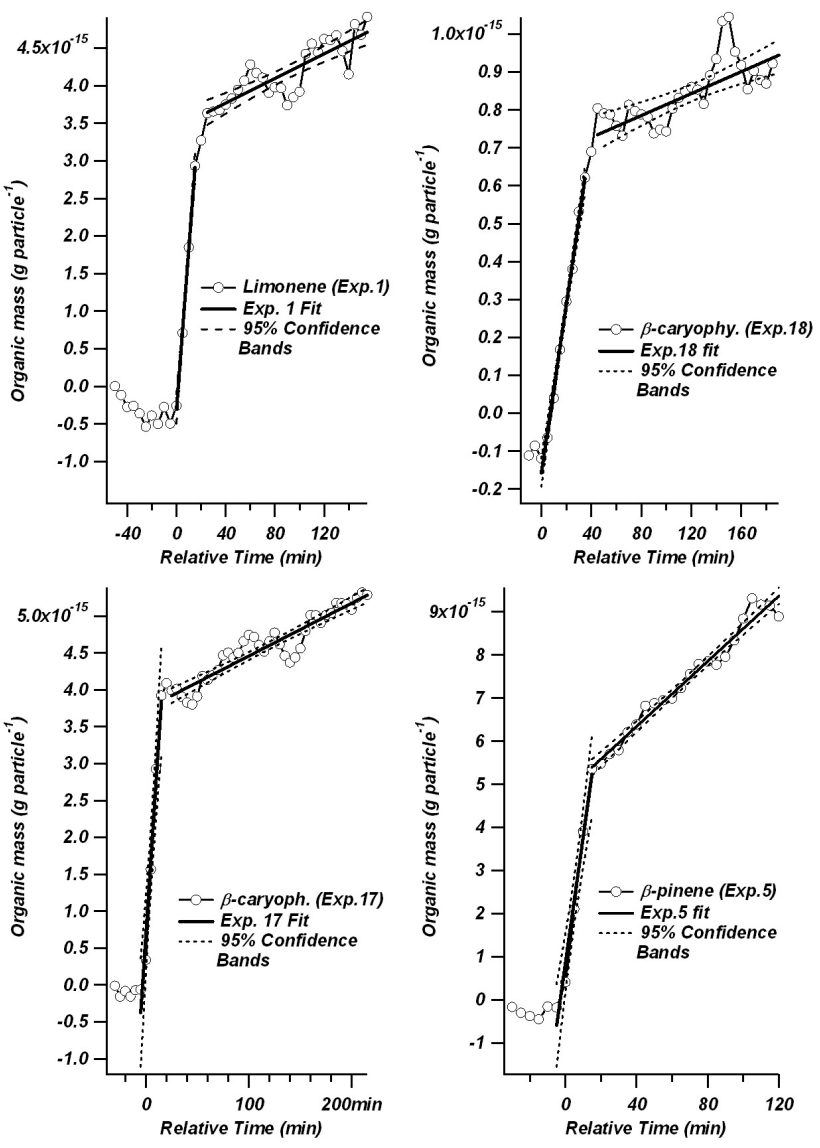

Fig. 8. Selected fits of uptake model to the organic mass per particle for the initial uptake phase and subsequent slow increase. Fit parameters were used to determine uptake coefficients.

hyde, and somewhat larger than those of glyoxal on aerosols (Liggio, et al., 2005), and other carbonyl species on sulfuric acid films (Iraci and Tolbert, 1997) or bulk solutions (Tolbert, et al., 1993). The implications of these uptake coefficients and equilibrium partition coefficients to the ambient atmosphere are discussed in the next section.

\section{Atmospheric significance}

The current experiments suggest that biogenic species, particularly those with functional groups containing oxygen, can be taken up directly to acidic aerosols without the need for prior oxidation in the gas phase, resulting in a large variety of polymeric structures, organic ethers and organosulfates. Given the vast array of unsaturated species present in the atmosphere of both biogenic and anthropogenic origin, it is likely that such processes could contribute to the atmospheric particle burden. The acidic nature of the aerosols in these experiments implies that these heterogeneous processes may be more relevant in the aerosols within power plant plumes, from freshly nucleated $\mathrm{H}_{2} \mathrm{SO}_{4}$ particles, on 
pre-existing aerosols on which $\mathrm{H}_{2} \mathrm{SO}_{4}$ has recently condensed, or in the free troposphere where particle acidity is expected to be high. Although the $\mathrm{pH}$ of aerosols in the lower troposphere has been reported as $\sim 3-5$ (Hindman, et al., 2006; Pszenny, et al., 2004), significantly lower aerosol $\mathrm{pH}$ values (-2.4-0.2) approaching the range of values used in this study $(-4.81-1.17)$, have also been reported (Ferek, et al., 1983; Li, et al., 1997; Katoshevski, et al., 1999). Due to the lack of aerosol acidity measurements, it is unclear how acidic particles might be in regions strongly influenced by biogenic activity. However, given that most nucleation events involve sulfuric acid, even in forested areas (Riipinen et al., 2007; S.-M. Li, personal communication), a significant uptake via this process may occur shortly after nucleation and the subsequent coagulation/condensational growth and prior to neutralization. The importance of polymerization to particle growth may be related to the duration required for such particles to become fully neutralized, which in turn depends on the available ammonia.

Although polymeric material has been identified in ambient aerosols (Kalberer, et al., 2006; Zappoli, et al.,1999; Denkenberger, et al., 2007) it is not possible to discern if they arise from polymerization of olefins by examining mass spectra alone. This is likely since levels are probably low, and BVOC (or other VOC) olefin polymers may not be obviously different than other types of polymers or high molecular weight hydrocarbons in a mass spectrometer. However, terpene-like polymers have been detected in ambient surface films (Lam, et al., 2005) which have been potentially attributed to secondary reactions. The results of this paper corroborate those ambient observations.

The irreversibility of some of the reactions, as observed by the residual organic after increases in RH (Fig. 3) has implications for the ambient atmosphere. Since increasing the RH in this study did not reduce the organic mass completely, heterogeneous products formed irreversibly at the onset of $\mathrm{H}_{2} \mathrm{SO}_{4}$ nucleation, or where acidic particles exist, may remain present even if subsequent neutralization or hydration of aerosols occurred. This suggests that typical measured neutral aerosols could also contain a significant amount of heterogeneous products from previous irreversible reactions as described here. Thus, organic mass correlations with particle acidity may not be a useful indicator of the polymerization process. Furthermore, equilibrium with water as demonstrated above may explain why attempts to quantify water soluble organic carbon (WSOC) as a measure of heterogeneous processing have been unsuccessful (Peltier, et al., 2007) ; particularly since collection of aerosols in aqueous solvents would inadvertently shift the equilibrium, and since what large molecular weight irreversible polymers remain after this shift are likely insoluble in water.

The possibility that polymer formation is concentration dependent and enhanced at the high gas phase levels during this study cannot be completely ruled out. However as noted previously, the fast initial uptake and the apparent dependence upon vapour pressure, make it more likely that mass accommodation is the controlling factor in this process. Also, significant organic uptake was nonetheless measured for several experiments performed under somewhat similar conditions but significantly lower gas-phase organic concentration. For example, Exp. 1 and 2 utilizing limonene at significantly different gas-phase concentrations did not have a significant effect on the uptake. In addition, the uptake of gases was observed over a large range of gas phase concentrations spanning $80 \mathrm{ppb}$ to $2.3 \mathrm{ppm}$. Previous studies of the oligomerization reactions of aldehydes (with a similar rate determining protonation step) in aerosols have also shown that there is no gas-phase concentration dependence for that process (Liggio and $\mathrm{Li}, 2006 \mathrm{~b}$ ). It may also be possible that rates of liquid phase oligomerization are limited by the fraction of SOA formed in the organic phase; ie: a liquid phase concentration dependence. Recent modelling efforts have shown that this could be an important effect (Chan, et al., 2007) although the effect for this study is currently unclear.

The estimates of partitioning coefficients $\left(K_{P, \text { eff }}\right)$ for monoterpenes and sesquiterpenes may be used to assess the potential for SOA formation via the near steady state processes observed in this study. Whether this steady state actually occurs in the atmosphere is not known. While the complexity of ambient aerosol processing may mean a steady state is never reached, and the applicability of these seed aerosols to the ambient atmosphere may be limited to situations where aerosol acidities are high, calculating $K_{p \text {,eff }}$ and applying it to the real atmosphere may be an instructive exercise, and a useful first step in understanding the importance of this process. Ambient gaseous monoterpene levels are somewhat variable but are typically measured in the range of $<0.1-2.5 \mathrm{ppb}$ per species (Hakola, et al., 2000; Harrison, et al., 2001) depending upon location. On the other hand, measurements of oxygenated terpenes and sesquiterpenes are very limited due primarily to technical difficulties associated with their measurement and their low ambient concentrations. Assuming a total simple terpene concentration of $10 \mathrm{ppb}$, a total oxygenated terpenes/sesquiterpene level of $100 \mathrm{ppt}$, and ambient aerosol levels of $30 \mu \mathrm{g} \mathrm{m}^{-3}$ (of significant acidity), and the average $K_{p \text {,eff }}$ values of Table 2 , upper and lower limits to the mass accumulated may be estimated. This simple calculation implies that $3.5-25 \mathrm{ng} \mathrm{m}^{-3}$ of terpene mass and $0.6-25 \mathrm{ng} \mathrm{m}^{-3}$ of sesquiterpene mass may form under steady-state conditions. This SOA burden is somewhat small, yet it is comparable to measured isoprene oxidation products, such as methyltetrols, and other condensable biogenic species which have been measured in ambient aerosols (Boge, et al., 2006; Li and Yu, 2005). These estimations are intended as lower and upper limits only but will change depending on ambient gaseous and aerosol levels. Under some circumstances concentrations significantly greater than $50 \mathrm{ppt}$ for a single oxygenated monoterpene may be possible (Hakola, et al., 2000), resulting in the potential for increased SOA mass via this steady state process. 
A perhaps more realistic scenario is encountered if it is assumed that a steady state is not achieved, especially if ambient aerosols are intermittently exposed to condensing $\mathrm{H}_{2} \mathrm{SO}_{4}$ during their lifetime (of which the acidity in unclear). In this case, the potential for SOA becomes more significant and can be estimated with the uptake coefficients of Table 2, by calculating a pseudo first order heterogeneous rate constant $\left(k_{\text {het }}=\frac{\gamma<c>S}{4}\right)$ where $S$ represents the total particle surface area. For this estimation $\mathrm{S}$ for a forested region was chosen to be $230 \mu \mathrm{m}^{2} \mathrm{~cm}^{-3}$ (Hoff, et al., 1996) although a significantly smaller $S$ is possible. Multiplying $k_{\text {het }}$ by the gas-phase concentration gives a heterogeneous rate $\left(\mu \mathrm{g} \mathrm{m}^{-3}\right.$ $\mathrm{s}^{-1}$ ), from which the potential aerosol mass can be estimated. This approach has been used on several occasions (Liggio and Li, 2006b; Liggio, et al., 2005). Using the mass accommodation coefficient $(\alpha)$ from the initial uptake region $k_{\text {het }}$ values of $1.36 \times 10^{-8}-1.6 \times 10^{-6} \mathrm{~s}^{-1}$ (simple monoterpenes) and $7.1 \times 10^{-8}-2.6 \times 10^{-4} \mathrm{~s}^{-1}$ (oxygenated monoterpenes and sesquiterpenes) were estimated. Such rate constants imply that this process is not a significant sink for gas phase species, as the lifetime due to heterogeneous reactions $\left(1 / k_{\text {het }}\right)$ were usually many orders of magnitude greater other gaseous sinks. Assuming the same gas phase concentrations as above, these estimates of heterogeneous formation rates may potentially result in $1.4 \pm 0.8 \mathrm{ng} \mathrm{m}^{-3}-160 \pm 73 \mathrm{ng}$ $\mathrm{m}^{-3}$ of organic mass from non-oxygenated monoterpenes and $0.11 \pm 0.06 \mathrm{ng} \mathrm{m}^{-3}-397 \pm 246 \mathrm{ng} \mathrm{m}^{-3}$ from oxygenated monoterpenes and sesquiterpenes in a relatively short time (30 min). These values likely represent an upper limit to such a process, and are predominantly dependent upon the value of the aerosol surface area used in the calculation, which could be significantly less at other locations. The coefficients derived in this work can be used to estimate the organic mass loading under these differing conditions. Although $397 \mathrm{ng} \mathrm{m}^{-3}$ may represent a somewhat significant depletion of sesquiterpenes from the assumed gas phase concentration, the experiments demonstrate that such a depletion is likely very temporary $(\sim 30 \mathrm{~min})$, slowing considerably as the aerosol surface becomes saturated, while the gaseous emissions continue. Nonetheless, such a particulate organic burden remains significant, particularly for freshly nucleated aerosols and potentially prior to any neutralization.

These estimates are highly dependent upon numerous factors including the particle-gas exposure time, ambient levels of these species, available acidity and surface area, but could nonetheless result in persistent oligomeric and organosulfate species in aerosols regardless of subsequent processing. Uptake coefficients reported here reflect the self reaction of one species in aerosols; given the vast array of unsaturated olefin containing compounds of natural and anthropogenic origin in the atmosphere, simultaneous uptake on aerosols may lead to mixed and complex oligomeric structures which have not been studied to this point. Nonetheless, reactive irreversible and reversible uptake of individual compounds is potentially an important contributor to SOA formation.
Edited by: G. McFiggans

\section{References}

Allan, J. D., Delia, A. E., Coe, H., Bower, K. N., Alfarra, M. R., Jimenez, J. L., Middlebrook, A. M., Drewnick, F., Onasch, T.B., Canagaratna, M. R., Jayne, J. T., and Worsnop, D. R.: A generalized method for the extraction of chemically resolved mass spectra from Aerodyne aerosol mass spectrometer data, J. Aerosol Sci., 35, 909-922, 2004.

Boge, O., Miao, Y., Plewka, A., and Herrmann, H.: Formation of secondary organic particle phase compounds from isoprene gasphase oxidation products: An aerosol chamber and field study, Atmos. Environ., 40, 2501-2509, 2006.

Chan, A. W. H., Kroll, J. H., Ng, N. L., and Seinfeld, J. H.: Kinetic modeling of Secondary Organic Aerosol formation: effects of particle- and gas-phase reactions of semivolatile products, Atmos. Chem. Phys., 7, 4135-4147, 2007,

http://www.atmos-chem-phys.net/7/4135/2007/.

Chandramouli, B., Jang, M., and Kamens Richard, M.: Gas-particle partitioning of semivolatile organic compounds (SOCs) on mixtures of aerosols in a smog chamber, Environ. Sci. Technol., 37, 18, 4113-4121, 2003.

Chwang, W. K., Nowlan, V. J., and Tidwell, T. T.: Reactivity of Cyclic and Acyclic Olefinic Hydrocarbons in Acid-Catalyzed Hydration, J. Am. Chem. Soc., 99(22), 7233-7238, 1977.

Clegg, S. L., Brimblecombe, P., and Wexler, A. S.: A thermodynamic model of the system H-NH4-Na-SO4-NO3-Cl-H2O at 298.15 K, J. Phys. Chem., 102A, 2155-2171, 1998.

Denkenberger, K. A., Moffet, R. C., Holecek, J. C., Rebotier, T. P., Prather, K. A.: Real-time, single- particle measurements of oligomers in aged ambient aerosol particles, Environ. Sci. Technol., 41(15), 5439-5446, 2007.

Eldering, A. and Cass, G. R.: Source-oriented model for air pollutant effects on visibility, J. Geophys. Res., 101(D14), 1934319369, 1996.

Ferek, R. J., Lazrus, A. L., Haagenson, P. L., and Winchester, J. W.: Strong and weak acidity of aerosols collected over the northeastern United States, Environ. Sci. Technol., 17, 315-324, 1983.

Gao, S., Ng, N. L., Keywood, M., Varutbangkul, V., Bahreini, R., Nenes, A., He, J., Yoo, K. Y., Beauchamp, J. L., Hodyss, R. P., Flagan, R. C., and Seinfeld, J. H.: Particle Phase Acidity and Oligomer Formation in Secondary Organic Aerosol, Environ. Sci. Technol., 38(24), 6582-6589, 2004.

Goldberg, M. S., Burnett, R. T., Valois, M.-F., Flegel, K., Bailar Iii, J. C., Brook, J., Vincent, R., and Radon, K.: Associations between ambient air pollution and daily mortality among persons with congestive heart failure, Environ. Res., 91(1), 8-20, 2003.

Hakola, H., Laurila, T., Rinne, J., and Puhto, K.:The ambient concentrations of biogenic hydrocarbons at a northern European, boreal site, Atmos. Environ., 34, 4971-4982, 2000.

Hannigan, M. P., Cass, G. R., Penmann, B. W., Crespi, C. L., Lafleur, A. L., Busby Jr., W. F., Thilly, W. G., and Simoneit, B. R. T.: Bioassay-directed chemical analysis of Los Angeles airborne particulate matter using a human cell mutagenicity assay, Environ. Sci. Technol., 32(22), 3502-3514, 1998.

Harrison, D., Hunter, M. C., Lewis, A. C., Seakins, P. W., Bonsang, B., Gros, V., Kanakidou, M., Touaty, M., Kavouras, I., Mi- 
halopoulos, N., Stephanou, E., Alves, C., Nunes, T., and Pio, C.: Ambient isoprene and monoterpene concentrations in a Greek (Abies Borisii-regis) forest. Reconciliation with emissions measurements and efects on measured $\mathrm{OH}$ concentrations, Atmos. Environ., 35, 4699-4711, 2001.

Hastings, W. P., Koehler, C. A., Bailey, E. L., and De Haan, D. O.: Secondary Organic Aerosol Formation by Glyoxal Hydration and Oligomer Formation: Humidity Effects and Equilibrium Shifts during Analysis, Environ. Sci. Technol., 39, 8728-8735, 2005.

Heald, C. L., Jacob, D. J., Park, R. J., Russell, L. M., Huebert, B. J., Seinfeld, J. H., Liao, H., and Weber, R. J.: A large organic aerosol source in the free troposphere missing from current models, Geophys. Res. Let., 32, L18809, doi:10.1029/2005GL023831, 2005.

Hindman, E. E., Borys, R. D., Lowenthal, D. H., and Phillip, N.: Long-term, wintertime aerosol, cloud and precipitation measurements in the northern Colorado Rocky Mountains, Atmos. Res., 82, 194-202, 2006.

Hoff, R. M., Guise-Bagley, L., Staebler, R. M., Wiebe, H. A., Brook, J., Georgi, B., and Dusterdiek, T.: Lidar, nephelometer, and in situ aerosol experiments in southern Ontario, J. Geophys. Res., 101(D14), 19 199-19209, 1996.

Hoffmann, T.: Adsorptive preconcentration technique including oxidant scavenging for the measurement of reactive natural hydrocarbons in ambient air, Fres. J. Anal. Chem., 351, 41-47, 1995.

Hoffmann, T., Odum, J. R., Bowman, F., Collins, D., Klockow, D., Flagan, R. C., and Seinfeld, J. H.: Formation of organic aerosols from the oxidation of biogenic hydrocarbons, J. Atmos. Chem., 26, 189-222, 1997.

Iinuma, Y., Müller, C., Böge, O., Gnauk, T., and Herrmann, H.: The formation of organic sulfate esters in the limonene ozonolysis secondary organic aerosol (SOA) under acidic conditions, Atmos. Environ., 41, 27, 5571-5583, 2007a.

Iinuma, Y., Muller, C., Berndt, T., Boge, O., Claeys, M., Herrmann, H.: Evidence for the Existence of Organosulfates from Pinene Ozonolysis in Ambient Secondary Organic Aerosol, Environ. Sci. Technol., 41,19, 6678-6683, doi:10.1021/es070938t, $2007 \mathrm{~b}$.

Iraci, L. T., and Tolbert, M. A.:Heterogeneous interaction of formaldehyde with cold sulfuric acid: implications for the upper troposphere and lower stratosphere, J. Geophys. Res., 102(D13), 16 099-16 107, 1997.

Jang, M., Carroll, B., Chandramouli, B., and Kamens Richard, M.: Particle growth by acid-catalyzed heterogeneous reactions of organic carbonyls on preexisting aerosols, Environ. Sci. Technol., 37(17), 3828-3837, 2003.

Jang, M. and Kamens, R. M.: Atmospheric secondary aerosol formation by heterogeneous reactions of aldehydes in the presence of a sulfuric acid aerosol catalyst, Environ. Sci. Technol., 35(24), 4758-4766, 2001.

Jayne, J. T., Leard, D. C., Zhang, X., Davidovits, P., Smith, K. A., Kolb, C. E., and Worsnop, D. R.: Development of an aerosol mass spectrometer for size and composition analysis of submicron particles, Aerosol Sci. Technol., 33(1-2), 49-70, 2000.

Jimenez, J. L., Jayne, J. T., Shi, Q., Kolb, C. E., Worsnop, D. R., Yourshaw, I., Seinfeld, J. H., Flagan, R. C., Zhang, X., Smith, K. A., Morris, J. W., and Davidovits, P.: Ambient aerosol sampling using the Aerodyne Aerosol Mass Spectrometer, J. Geo- phys. Res., 108(D7), SOS 13/1-SOS 13/13, 2003.

Kalberer, M., Paulsen, D., Sax, M., Steinbacher, M., Dommen, J., Prevot, A. S. H., Fisseha, R., Weingartner, E., Frankevich, V., Zenobi, R., and Baltensperger, U.: Identification of polymers as major components of atmospheric organic aerosols, Science, 303(5664), 1659-1662, 2004.

Kalberer, M., Sax, M., and Samburova, V.: Molecular size evolution of oligomers in organic aerosols collected in urban atmospheres and generated in a smog chamber, Environ. Sci. Technol., 40(19), 5917-5922, 2006.

Katoshevski, D., Nenes, A., and Seinfeld, J. H.: A study of processes that govern the maintenance of aerosols in the marine boundary layer, J. Aerosol Sci., 30(4), 503-532, 1999.

Kavouras, I. G., Mihalopoulos, N., and Stephanou, E. G.: Secondary organic aerosol formation vs primary organic aerosol emission: In situ evidence for the chemical coupling between monoterpene acidic photooxidation products and new particle formation over forests, Environ. Sci. Technol., 33(7), 10281037, 1999.

Kroll, J. H., Ng, N. L., Murphy, S. M., Flagan, R. C., and Seinfeld, J. H.: Secondary Organic Aerosol Formation from Isoprene Photooxidation, Environ. Sci. Technol., 40(6), 1869-1877, 2006.

Kroll, J. H., Ng, N. L., Murphy, S. M., Varutbangkul, V., Flagan, R. C., and Seinfeld, J. H.: Chamber studies of secondary organic aerosol growth by reactive uptake of simple carbonyl compounds, J. Geophys. Res., 110, D23207, doi:10.1029/2005JD006004, 2005.

Li, S.-M., Macdonald, A. M., Strapp, J. W., Lee, Y. N., and Zhou, $\mathrm{X}$. L.:Chemical and physical characterizations of atmospheric aerosols over southern California, J. Geophys. Res., 102(D17), $21341-21353,1997$.

Li, Y.-C. and Yu, J. Z.: Simultaneous Determination of Mono- and Dicarboxylic Acids, ö-Oxo-carboxylic Acids, Midchain Ketocarboxylic Acids, and Aldehydes in Atmospheric Aerosol Samples, Environ. Sci. Technol., 39, 7616-7624, 2005.

Liggio, J., and Li, S.-M.: Organosulfate formation during the uptake of Pinonaldehyde on Acidic Sulfate Aerosols, Geophys. Res. Let., 33, L13808, doi:10.1029/2006GL026079, 2006a.

Liggio, J. and Li, S.-M.: Reactive Uptake of Pinonaldehyde on Acidic Aerosols, J. Geophys. Res., 111, D24303, doi:10.1029/2005JD006978, 2006b.

Liggio, J., Li, S.-M., Brook, J. R., and Mihele, C.: Direct polymerization of isoprene and $\alpha$-pinene on acidic aerosols, Geophys. Res. Let., 34, L05814, doi:10.1029/2006GL028468, 2007.

Liggio, J., Li, S.-M., and Mclaren, R.: Reactive uptake of glyoxal by particulate matter, J. Geophys. Res., 110, D10304, doi:10.1029/2004JD005113, 2005.

Limbeck, A., Kulmala, M., and Puxbaum, H.: Secondary organic aerosol formation in the atmosphere via heterogeneous reaction of gaseous isoprene on acidic particles, Geophys. Res. Let., 30(19), 1996, 2003.

Noziere, B. and Riemer, D.D.: The chemical processing of gasphase carbonyl compounds by sulfuric acid aerosols: 2,4pentandione, Atmos. Environ., 37, 841-851, 2003.

Pankow, J.F.:An absorption model of the gas/aerosol partitioning involved in the formation of secondary organic aerosol, Atmos. Environ., 28, 2, 189-193, 1994.

Peltier, R. E., Sullivan, A. P., Weber, R. J., Wollny, A. G., Holloway, J. S., Brock, C. A., Gouw, J. A. D., and Atlas, E. L.: No evidence 
for acid-catalyzed secondary organic aerosol formation in power plant plumes over metropolitan Atlanta, Georgia, Geophys. Res. Let., 112, D10S18, doi:10.1029/2006JD007515, 2007.

Pilinis, C., Pandis, S. N., and Seinfeld, J. H.: Sensitivity of direct climate forcing by atmospheric aerosols to aerosol size and composition, J. Geophys. Res., 100(D9), 18 739-18 754, 1995.

Pszenny, A. A., Moldanova, J., Keene, W. C., Sander, R., Maben, J. R., Martinez, M., Crutzen, P. J., Perner, D., Prinn, R. G.: Halogen cycling and aerosol $\mathrm{pH}$ in the Hawaiian marine boundary layer, Atmos. Chem. Phys., 4, 147-168, 2004, http://www.atmos-chem-phys.net/4/147/2004/.

Riipinen, I., Sihto, S.-L., Kulmala, M., Arnold, F., Dal Maso, M., Birmili, W., Saarnio, K., Teinila, K., Kerminen, V.-M. Laaksonen, A., and Lehtinen, K. E. J.: Connections between atmospheric sulphuric acid and new particle formation during QUEST III-IV campaigns in Heidelberg and Hyytiala, Atmos. Chem. Phys., 7, 1899-1914, 2007, http://www.atmos-chem-phys.net/7/1899/2007/.

Shi, Q., Davidovits, P., Jayne, J. T., Worsnop, D. R., and Kolb, C. E.: Uptake of gas-phase ammonia, 1. Uptake by aqueous surfaces as a function of pH, J. Phys. Chem., 103, 8812-8823, 1999.

Slebocka-Tilk, H. and Brown, R. S.: Acid-Catalyzed Hydration of anti-sesquinorbornene, J. Org. Chem., 61, 8079-8082, 1996.

Steinbacher, M., Dommen, J., Ammann, C., Spirig, C., Neftel, A., and Prevot, A. S. H.: Performance characteristics of a protontransfer-reaction mass spectrometer (PTR-MS) derived from laboratory and field measurement, Int. J. Mass Spectrom., 239, $117-$ 128, 2004.
Surratt, J. D., Kroll, J. H., Kleindienst, T. E., Edney, E. O., Claeys, M., Sorooshian, A., Ng, N. L., Offenberg, J. H., Lewandowski, M., Jaoui, M., Flagan, R. C., and Seinfeld, J. H.: Evidence for Organosulfates in Secondary Organic Aerosol, Environ. Sci. Technol., 41(2), 517-527, 2007.

Tolbert, M. A., Pfaff, J., Jayaweera, I., and Prather, M. J.: Uptake of formaldehyde by sulfuric acid solutions: Impact on stratospheric ozone, J. Geophys. Res., 98(D2), 2957-2962, 1993.

Tolocka, M. P., Jang, M., Ginter, J. M., Cox, F. J., Kamens, R. M., and Johnston, M. V.: Formation of Oligomers in Secondary Organic Aerosol, Environ. Sci. Technol., 38(5), 1428-1434, 2004.

Wade, L. G.: Organic chemistry, Prentice Hall, Upper Saddle River, N.J, 2003.

Zappoli, S., Andracchio, A., Fuzzi, S., Facchini, M. C., Gelencser, A., Kiss, G., Krivacsy, Z., Molnar, A., Meszaros, E., Hansson, H. C., Rosman, K., Zebuhr, Y.: Inorganic, organic and macromolecular components of fine aerosol in different areas of Europe in relation to their water solubility, Atmos. Environ. 33, 2733-2743, 1999. 